\title{
Numerical Modelling of Prestresssing Steel Tendons under Fire and Post- fire Conditions
}

\author{
Ya Wei and Francis T K Au* \\ The University of Hong Kong, Department of Civil Engineering
}

\begin{abstract}
The behaviour of prestressing steel tendons under fire and post-fire conditions is investigated numerically employing the ABAQUS package and its user-defined material subroutine UMAT which allows comprehensive constitutive relationships to be implemented. Based on an existing thermal creep model, a new set of parameters are proposed and calibrated against available test results in the literature. The proposed numerical model is versatile in predicting thermal creep, isothermal response and transient thermal relaxation of prestressing steel tendons. Moreover, parametric studies are conducted to investigate the effects of heating rate, heated length ratio, initial stress and various boundary conditions on the thermal relaxation of prestressing steel tendons. Besides, transient state analyses are carried out with constant heating rate and initial stress to investigate the rupture properties of prestressing steel tendons.
\end{abstract}

Keywords: fire resistance, numerical modelling, prestressing steel, thermal creep

\section{INTRODUCTION}

Post-tensioned (PT) concrete slabs are increasingly used in modern buildings as they can achieve higher span to depth ratios. This is made possible by prestressing steel tendons (i.e. strands or wires) with suitable arrangement and profiles (e.g. parabolic, deflected or straight) carrying high stresses to induce membrane compression in the slabs, thereby enhancing their load-carrying capacities. However, once the slabs are subjected to fire, the tendon stresses will be significantly affected for various reasons, such as degradation of mechanical properties, thermal elongation and thermal creep deformation at elevated temperatures. More

*Corresponding author: Professor F. T. K. Au;

E-mail: francis.au@hku.hk;

Tel: (852) 2859-2650; Fax: (852) 2559-5337;

Address: Department of Civil Engineering, The University of Hong Kong, Pokfulam Road, Hong Kong, China. 
importantly, the slab may collapse if the tendon stresses are greatly reduced, or if the tendons rupture. Besides, permanent loss in tendon stress may occur in a fire, and hence the residual load-carrying capacity should be carefully evaluated for safety. Therefore, it is necessary to model accurately the behaviour of prestressing steel tendons under high stresses during and after exposure to elevated temperatures.

Although the fire resistance of PT concrete slabs has been studied, more work is desirable to understand better the behaviour of prestressing steel tendons in and after fire. In early 1970s, Gustaferro (1973) reported a series of fire tests of PT concrete slabs and beams under standard fire condition (ASTM E119), highlighting the importance of concrete cover to the prestressing steel, based on which prescribed fire design procedures were presented. However it is unknown how the prestressing steel tendons have behaved. In the recent decade, more fire tests of PT concrete slabs under standard fire condition (ISO 834) were conducted mainly in China and the UK. Yuan et al. (2006) and Gao et al. (2004) conducted fire tests of unbonded PT concrete one-way slabs, investigating their responses in fire. The variations of tendon forces were recorded, often indicating slight increase in tendon force initially followed by significant decrease or even rupture. Around the same time, Zheng et al. (2010) and Zheng and Hou (2008) also conducted tests of unbonded PT concrete slabs in fire, mainly focusing on concrete spalling. The variations of tendon forces were recorded as well, but the results were not presented. Bailey and Ellobody (2009a, 2009b) conducted a series of fire tests of simply-supported bonded and unbonded PT concrete slabs under standard fire conditions (ISO 834). The failure mechanisms of the slabs were investigated and the strains of the prestressing steel strands were recorded. Some strands even ruptured in the tests, so the temperatures of strands were controlled at around $400^{\circ} \mathrm{C}$ to avoid the rupture again. Numerical work was also conducted by Ellobody and Bailey $(2008,2009,2011)$. However, the specific behaviour of strands has not been presented in detail. The behaviour of prestressing steel tendons during and after exposure to elevated temperatures as an issue needs to be addressed for improving the fire resistance design of PT concrete slabs and the evaluation of their residual load-carrying capacities after fire.

To investigate the behaviour of prestressing steel strands under high stresses at elevated temperatures, tests have been conducted by MacLean (2007), though without considering the interaction with concrete. A local heating-soaking-cooling regime was applied on the strands to investigate the stress variation in the whole process, and permanent stress loss after elevated temperatures. Based on the tests, Gales (2009) further conducted a series of tests of strands with more practical length accounting for multi-span continuous PT 
floors. The strands were placed in a parabolic form to simulate the actual configuration. A local heatingsoaking-cooling regime was also applied but with smaller heated length ratio, namely ratio of heated length to the total length of prestressing strand. The investigations indicated that the strands with smaller heated length ratio were prone to rupture. A linear computational model was developed by MacLean and further improved by Gales to study the responses of the strands. However, the results obtained from the computational model did not agree well with the test results due to dubious thermal creep parameters used in the model (Gales et al. 2009). To clarify the behaviour of the prestressing steel strands during and after elevated temperatures, Atienza and Elices (2009) have also conducted tests to investigate fire-induced damage on prestressing strands, accounting for the reduction of mechanical properties, stress relaxation and permanent stress loss. The tests have provided useful information on the behaviour of prestressing steel with high initial stresses at elevated temperatures, but more can be done by numerical modelling to provide better insight. It is desirable to develop a robust nonlinear numerical model to simulate the behaviour of strands during and after exposure to elevated temperatures taking into account time-independent plastic strain, thermal creep strain, possible rupture, and changes of mechanical properties. The capability of the model in simulating the behaviour of strands in prestressed concrete structures in and after typical fire scenarios will be thoroughly examined with a view to predicting the failure of strands.

\section{NUMERICAL MODEL}

The behaviour of prestressing steel during and after exposure to elevated temperatures is quite complex, encompassing elastic and time-independent plastic deformations, thermal expansion and thermal creep, which all contribute to the responses of prestressing steel. To help identify the mechanism behind the complex behaviour, a numerical model is developed employing the finite element package ABAQUS using 3-dimensional solid element C3D8R in stress analysis and DC3D8 in thermal analysis, while the material constitutive relationship is programmed and implemented in the user-defined material subroutine UMAT in ABAQUS. In view of the complex geometry of 7-wire strands and the intertwined conditions in common multi-strand cables, a simplified model in the form of a circular rod with equivalent cross-sectional area is adopted for practicality. The finite element mesh adopted for both wires and strands consists of a bundle of four longitudinal columns of identical prismatic 8-node solid elements such that each quadrant of the circular section is approximated by a quadrilateral. 


\subsection{Comprehensive Constitutive Relationship}

The total strain $\varepsilon_{t o t}$ at an integration point can be expressed in terms of four strain components as

$$
\varepsilon_{t o t}=\varepsilon_{e}(\sigma, T)+\varepsilon_{p}(\sigma, T)+\varepsilon_{T}(T)+\varepsilon_{c r}(\sigma, t, T)
$$

where the elastic strain $\varepsilon_{e}(\sigma, T)$ and time-independent plastic strain $\varepsilon_{p}(\sigma, T)$ are functions of stress $\sigma$ and temperature $T$, the thermal expansion $\varepsilon_{T}(T)$ depends only on temperature $T$ and is recoverable, and the thermal creep strain $\varepsilon_{c r}(\sigma, t, T)$, which depends on stress $\sigma$, time $t$ and temperature $T$, is irrecoverable. The indices tot, $e, p, T$ and $c r$, which denote quantities of the total strain, elastic strain, time-independent plastic strain, thermal expansion strain and thermal creep strain, respectively, will also be used in other symbols. The stress increment over the time interval from $t_{n}$ to $t_{n+1}$ and the stress at time $t_{n+1}$ are respectively given by

$$
\begin{gathered}
\Delta \sigma_{i j}=C_{i j k l}\left(\Delta \varepsilon_{k l}^{t o t}-\Delta \varepsilon_{k l}^{p}-\Delta \varepsilon_{k l}^{T}-\Delta \varepsilon_{k l}^{c r}\right) \\
\sigma_{i j}^{n+1}=\sigma_{i j}^{n}+\Delta \sigma_{i j}
\end{gathered}
$$

where $\Delta \sigma_{i j}$ is the stress increment tensor; $\sigma_{i j}^{n+1}$ and $\sigma_{i j}^{n}$ are the stress tensors at time $t_{n+1}$ and $t_{n}$, respectively; $\Delta \varepsilon_{k l}^{t o t}, \Delta \varepsilon_{k l}^{p}, \Delta \varepsilon_{k l}^{T}$ and $\Delta \varepsilon_{k l}^{c r}$ are the strain increment tensor components for the total strain, elastic strain, time-independent plastic strain, thermal expansion strain and thermal creep strain, respectively; $C_{i j k l}$ is the isotropic fourth order tensor (i.e. Hooke's elastic operator) given as $C_{i j k l}=$ $G\left(\delta_{i k} \delta_{j l}+\delta_{i l} \delta_{j k}\right)+\left(K-\frac{2}{3} G\right) \delta_{i j} \delta_{k l}$ in which $\delta_{i j}$ is the Kronecker delta; $G$ and $K$ are the shear and bulk moduli respectively given in terms of the elastic modulus $E$ and the Poisson's ratio $v$ as $G=$ $2 E /(1+v)$ and $K=E /[3(1-2 v)]$.

For the time-independent mechanical constitutive relationship during and after exposure to elevated temperatures, von Mises yield criteria with the associated plastic flow rule and linear strain hardening plasticity can be used to predict plastic deformation and possible rupture, namely

$$
F=J_{2}-R^{2}\left(\varepsilon_{e q}\right)
$$

where $F$ is the von Mises yield function, $J_{2}$ is the second invariant of the deviatoric stress tensor $s_{i j}$; and $R$ is the hardening function of equivalent plastic strain $\varepsilon_{e q}$. Thus, the plastic strain increment $\Delta \varepsilon_{i j}^{p}$ over the time interval from $t_{n}$ to $t_{n+1}$ is given in terms of the plastic multiplier $d \lambda$ by

$$
\Delta \varepsilon_{i j}^{p}=d \lambda \frac{\partial F}{\partial \sigma}=d \lambda s_{i j}
$$


Moreover, the elastic modulus, yield strength and ultimate strength all deteriorate with temperature. While the elastic modulus can recover after cooling to the state before heating, the yield strength and ultimate strength are reduced permanently. The residual yield and ultimate strengths are governed by the maximum temperature reached in the heating-cooling process. Besides, during the cooling process, the yield and ultimate strengths are often obtained by linear extrapolation between the strengths at maximum temperature and residual strengths at ambient temperature. The empirical equation proposed by MacLean (2007) accounting for reduction of elastic modulus at elevated temperatures is

$$
\frac{E_{T}}{E_{20}}=-2 \times 10^{-6} T^{2}+0.2 \times 10^{-6} T+0.987
$$

where $E_{T}$ denotes the elastic modulus at temperature $T\left({ }^{\circ} \mathrm{C}\right)$ during the cooling process, which lies between the maximum elevated temperature and the ambient temperature; and $E_{20}$ denotes the elastic modulus at ambient temperature. Unless otherwise stated, the strain hardening modulus accounting for the assumed linear hardening is taken as $2.5 \%$ of the elastic modulus.

According to Eurocode 2 Part 1-2 (2004), the reduction factor $k$ for "yield" strength and ultimate strength of prestressing wires and strands at elevated temperature $T\left({ }^{\circ} \mathrm{C}\right)$ is given as

for $20^{\circ} \mathrm{C} \leq T \leq 100^{\circ} \mathrm{C}$

$$
k=1
$$

for $100^{\circ} \mathrm{C} \leq \mathrm{T} \leq 350^{\circ} \mathrm{C}$

$$
k=1.0-0.45(T-100) / 250
$$

for $350^{\circ} \mathrm{C} \leq \mathrm{T} \leq 550^{\circ} \mathrm{C}$

$$
k=0.55-0.45(T-350) / 200
$$

for $550^{\circ} \mathrm{C} \leq \mathrm{T} \leq 1200^{\circ} \mathrm{C}$

$$
k=0.1-0.1(T-550) / 650
$$

After heating and cooling, the residual "yield" strength and ultimate strength can be obtained by the empirical reduction factor $\bar{k}$ proposed by Hertz (2004) as

$$
\bar{k}=\varphi+\frac{1-\varphi}{1+\left(\frac{T}{T_{1}}\right)+\left(\frac{T}{T_{2}}\right)^{2}+\left(\frac{T}{T_{8}}\right)^{8}+\left(\frac{T}{T_{64}}\right)^{64}}
$$

where $T\left({ }^{\circ} \mathrm{C}\right)$ here is the maximum temperature reached during heating; and the other parameters are $\left(\varphi, T_{1}, T_{2}, T_{8}, T_{64}\right)=(0.2,100000,750,550)$.

The thermal strain of prestressing steel at temperature $T\left({ }^{\circ} \mathrm{C}\right)$ can be determined with reference to the length at $20^{\circ} \mathrm{C}$ as Eurocode 2 Part 1-2 (2004)

for $20^{\circ} \mathrm{C} \leq \mathrm{T} \leq 1200^{\circ} \mathrm{C}$ 


$$
\varepsilon_{T}(T)=-2.016 \times 10^{-4}+10^{-5} T+0.4 \times 10^{-8} T^{2}
$$

Assuming isotropic thermal strain, the thermal strain increment tensor over the time interval from $t_{n}$ to $t_{n+1}$ can be expressed as

$$
\Delta \varepsilon_{i j}^{T}=\left[\varepsilon_{T}\left(T_{n+1}\right)-\varepsilon_{T}\left(T_{n}\right)\right] \delta_{i j}
$$

where $T_{n+1}$ and $T_{n}$ are the temperatures in degree Celsius at time $t_{n}$ and $t_{n+1}$ respectively.

Thermal creep is always defined as the time-dependent plastic strain under constant stress and temperature. Normally, thermal creep strain or strain increment is obtained as a uniaxial quantity by

$$
\Delta \varepsilon_{c r}=f\left(\bar{\sigma}_{n}, t_{n+1}, T_{n+1}\right)-f\left(\bar{\sigma}_{n}, t_{n}, T_{n}\right)
$$

where $f$ is the thermal creep function of stress, time and temperature; and $\bar{\sigma}_{n}$ is the equivalent stress at time $t_{n+1}$ that is at the end of time step $n$. In triaxial conditions, it is assumed that the creep deformation depends on the deviatoric stress and the thermal creep strain increment tensor can be described by Naumenko and Altenbach (2007).

$$
\Delta \varepsilon_{i j}^{c r}=\frac{3 \Delta \varepsilon_{c r}}{2 \bar{\sigma}_{n}} s_{i j}^{n}
$$

where $s_{i j}^{n}$ is the deviatoric stress tensor in time step $n$.

\subsection{Procedure of Analysis}

The numerical model is analysed in a sequentially coupled thermal-stress analysis procedure by ABAQUS (Wei and Au 2011). Heat transfer analysis is carried out by the solid element DC3D8 while structural analysis is conducted by the solid element C3D8R adopting the enhanced algorithm to avoid the hourglass effects.

Firstly, transient thermal analysis is conducted using the thermal properties (e.g. thermal conductivity, thermal film coefficient and thermal radiant coefficient) taken from Eurocode 1 Part 1-2 (2002) and Eurocode 2 Part 1-2 (2004). The ambient temperature of the model is taken as $20^{\circ} \mathrm{C}$. The temperature around the heated zone is prescribed according to the actual heating conditions, while that outside the heated zone is set to be the ambient temperature. The transient thermal analysis then provides the variations of temperature field with time.

Secondly, stress analysis at elevated temperature is conducted by the standard finite element procedure in ABAQUS to obtain the total strains at integration points, which are passed to the user-defined material subroutine UMAT for prediction of stress increment and hence the final stress at the end of each time 
interval. In the process, judgment is made on whether the predicted stress violates the yield criterion. Once the yield criterion is violated, the implicit integration algorithm is used to bring the stress back to the yield surface. The predicted stress is then updated for analysis in the next time interval.

\section{CREEP THEORY AND MODEL}

During a fire, the thermal creep deformation in prestressing tendons of PT concrete slabs will be a key factor influencing their performance. Prestressing steel of different chemical compositions invariably contains some defects of microstructure, which may cause movement of lattice dislocations under high stresses or diffusion under elevated temperatures. Thermal creep deformation can be categorized into two kinds, namely solid state diffusion dominated creep, and glide or sliding dominated creep (Poirier 1985). The former mechanism occurs at lower stress and higher temperature and the creep strain is determined by the rate of solid state diffusion in the bulk of crystal grains or along grain boundaries, or by extensive diffusion-assisted dislocation climb for larger grain sizes. The latter mechanism occurs at higher stress and lower temperature, and the creep strain is determined by dislocation motion assisted by vacancy diffusion, dislocation slip over crystallographic planes which prevail at room temperature, with individual grains sliding over each other under the conditions of relatively higher stress and temperature.

The three stages of creep (Kodur and Dwaikat 2010) are shown in Figure 1(a). Primary creep as the first stage develops rapidly but at decreasing strain rate. Secondary creep as the second stage develops linearly at a strain rate that remains nearly constant. Tertiary creep as the third stage is characterized by accelerated strain rate until rupture. Among various stages, secondary creep is of great concern at elevated temperatures, and the secondary creep rate obeys Arrhenius's Law given as

$$
\frac{\partial \varepsilon_{\mathrm{cr}}}{\partial \mathrm{t}} \propto \exp \left(-\frac{Q_{c}}{R \bar{T}}\right) \quad \frac{\mathrm{d} \sigma}{\mathrm{dt}}=0
$$

where $\varepsilon_{c r}$ is the creep strain; $t$ is time; $Q_{c}$ is the activation energy for thermal creep, which is roughly the activation energy for lattice self-diffusion when it is above half of the melting temperature (in Kelvin); $R$ is the gas constant; $\bar{T}$ is the temperature in Kelvin; and $\sigma$ is the creep stress in MPa.

According to Dorn's creep theory as presented by Harmathy (1967), the temperature-compensated time $\theta$ is defined by

$$
\theta=\int_{0}^{t} \exp \left(-\frac{Q_{c}}{R \bar{T}}\right) d t
$$


Differentiating Eqn 14 with respect to time $t$, and substituting into Eqn 13 give

$$
\frac{\partial \varepsilon_{c r}}{\partial \theta}=\frac{\partial \varepsilon_{c r}}{\partial t} \exp \left(\frac{Q_{c}}{R \bar{T}}\right) \equiv Z
$$

where $Z$ is the Zener-Hollomon parameter (in $\mathrm{hr}^{-1}$ ), which is taken as a function of stress but independent of temperature as shown in Figure 1(b). The dimensionless parameter $\varepsilon_{c r, 0}$ in Figure 1(b) is obtained by extending the straight line for secondary creep to the $\varepsilon_{c r}$ axis, and is uniquely determined by stress but independent of temperature as well.

The identification of parameters $Q_{c}, Z$ and $\varepsilon_{c r, 0}$ are important. For prestressing steel, Harmathy and Stanzak (1970) have proposed the corresponding values for ASTM A421 (Grade 1725). Gales et al. (2012) have proposed the corresponding values for BS 5896 (Grade 1860) and ASTM A416 (Grade 1860). In this study, a new set of values are proposed here based on the tests conducted by Zhang and Zheng (2006) for prestressing steel to GB/T 5224 (Grade 1770) as shown and compared with other available sets of parameters below:

ASTM A421

(Grade 1725)

(Harmathy and Stanzak 1970)

GB/T 5224

(Grade 1770)

ASTM A416

(Grade 1860)

(Gales et al. 2012)

BS 5896

(Grade 1860)

(Gales et al. 2012)
$Z=195.27 \times 10^{6} \sigma^{3}$

$Z=8.21 \times 10^{13} e^{0.0145 \sigma}$

$\varepsilon_{c r, 0}=9.262 \times 10^{-5} \sigma^{0.67}$

$Q_{c} / R=30556$

$Z=1.44836 \times 10^{14} e^{0.01355 \sigma}$

$Z=3.7032 \times 10^{11} e^{0.02136 \sigma}$

$\varepsilon_{c r, 0}=6.00734 \times 10^{-4} \sigma^{0.25105}$

$Q_{c} / R=30556$

$Z=2.7 \times 10^{13} e^{0.012 \sigma}$

$\varepsilon_{c r, 0}=1.13 \times 10^{-7} \sigma^{1.63}$

$Q_{c} / R=30556$

$Z=1.60 \times 10^{12} e^{0.013 \sigma}$

$Z=3.42 \times 10^{4} e^{0.30 \sigma}$

$\varepsilon_{c r, 0}=1.51 \times 10^{-14} \sigma^{3.90}$

$Q_{c} / R=30556$ for $\sigma \leq 172 \mathrm{MPa}$

for $172<\sigma \leq 690 \mathrm{MPa}$

for $\sigma \leq 690 \mathrm{MPa}$

for $250 \leq \sigma \leq 751 \mathrm{MPa}$

for $751 \leq \sigma \leq 1169 \mathrm{MPa}$

for $250 \leq \sigma \leq 1169 \mathrm{MPa}$

for $690<\sigma<1000 \mathrm{MPa}$

for $690<\sigma<1000 \mathrm{MPa}$

for $690<\sigma<1000 \mathrm{MPa}$

for $1000<\sigma<1200 \mathrm{MPa}$

for $690<\sigma<1200 \mathrm{MPa}$

Figure 2 shows that steels to GB/T 5224 (Grade 1770) and ASTM A421 (Grade 1725) (Harmathy and 
Stanzak 1970) have nearly the same temperature-compensated creep rates, which are much higher than those of ASTM A416 (Grade 1860) and BS 5896 (Grade 1860) (Gales et al. 2012).

Harmathy (1967) have proposed two slightly different equations to describe the primary thermal creep strain with the aid of creep parameters of $Z$ and $\varepsilon_{c r, 0}$ as

$$
\begin{aligned}
\frac{1}{z} \frac{d \varepsilon_{c r}}{d \theta} & =\operatorname{coth}\left(\ln 2 \frac{\varepsilon_{c r}}{\varepsilon_{c r, 0}}\right) & \frac{d \sigma}{d t} & =0 \\
\frac{1}{z} \frac{d \varepsilon_{c r}}{d \theta} & =\operatorname{coth}^{2}\left(\frac{\varepsilon_{c r}}{\varepsilon_{c r, 0}}\right) & \frac{d \sigma}{d t} & =0
\end{aligned}
$$

Eqn 16 can be integrated to give

$$
\varepsilon^{c r}=\frac{\varepsilon_{c r, 0}}{\ln 2} \cosh ^{-1}\left(2^{Z \theta / \varepsilon_{c r, 0}}\right) \quad \frac{d \sigma}{d t}=0
$$

However, Eqn 17 cannot be integrated explicitly, but it can be expressed in incremental form over a time interval as

$$
\Delta \varepsilon^{c r}=Z \operatorname{coth}^{2}\left(\frac{\varepsilon^{c r}}{\varepsilon_{c r, 0}}\right) \Delta \theta \quad \frac{d \sigma}{d t}=0
$$

In the following sections, two models will be investigated, including Model-1 based on Eqn 18 and Model2 based on Eqn 19.

\section{RESULTS AND DISCUSSIONS}

The proposed numerical models are then validated against available test results, including thermal creep tests, isothermal relaxation tests and transient relaxation tests. In addition, the effects of adopting different sets of parameter are also investigated.

\subsection{Modelling of Thermal Creep}

Based on the thermal creep tests conducted by Zhang and Zheng (2006), the above two creep models and four sets of thermal creep parameters are examined in detail. In the tests, prestressing steel wire to GB/T 5224 (Grade 1770) was investigated. The specimens used had a diameter of $5.02 \mathrm{~mm}$, “yield” strength $(0.2 \%$ offset strain) of $1412 \mathrm{MPa}$, ultimate strength of $1803 \mathrm{MPa}$, and elastic modulus of $204 \mathrm{GPa}$. An extensometer with gauge length of $25 \mathrm{~mm}$ was used to measure thermal creep strains. To model a $25 \mathrm{~mm}$ length of wire, 20 solid elements are used. Comparisons are carried out between the test results of Zhang and Zheng (2006) and numerical results as shown in Figures 3 to 5.

Figure 3 shows that the numerical predictions using the thermal creep parameters of GB/T 5224 (Grade 
1770) and ASTM A421 (Grade 1725) are consistent with the test results in their applicable stress ranges. Figure 3(a) for the stress of $250 \mathrm{MPa}$ indicates that the two creep models with their respective thermal creep parameters can accurately predict the thermal creep strains. Under the stress of 501MPa, Figure 3(b) shows increasing discrepancies at the temperature of $450^{\circ} \mathrm{C}$, but good agreement at the temperatures of $400^{\circ} \mathrm{C}$ and $350^{\circ} \mathrm{C}$. Under the stress of $751 \mathrm{MPa}$ as shown in Figure 3(c), the numerical predictions are slightly below the test results at the temperatures of $300^{\circ} \mathrm{C}$ and $350^{\circ} \mathrm{C}$. Figure $3(\mathrm{~d})$ for the stress of 1002 MPa still shows good agreement between the numerical predictions and test results. The thermal creep parameters obtained for GB/T 5224 (Grade 1770) give reasonable results. In comparison, Model-2 performs better than Model-1 especially at relatively low temperatures (e.g. up to $300^{\circ} \mathrm{C}$ ).

Figure 4 shows the numerical predictions using the thermal creep parameters of ASTM A416 (Grade 1860) compared with the test results of Zhang and Zheng (2006) for GB/T 5224 (Grade 1770). Figure 4(a) for the stress of 751 MPa shows predicted results departing with time from test results at various temperatures. Besides, under the stress of $1002 \mathrm{MPa}$ as shown in Figure 4(b), the discrepancies are much larger, with the predicted strains well below those from the tests. It may suggest that prestressing steel to ASTM A416 (Grade 1860) is more resistant to thermal creep than GB/T 5224 (Grade 1770).

Figure 5 shows the predicted creep strains using the thermal creep parameters of BS 5896 (Grade 1860) compared with the test results of Zhang and Zheng (2006) for GB/T 5224 (Grade 1770). The predicted strains are obviously much lower than the test results for various stresses and temperatures, which may further suggest that prestressing steel to BS 5896 (Grade 1860) is more resistant to thermal creep than ASTM A416 (Grade 1860) and GB/T 5224 (Grade 1770).

In summary, the thermal creep parameters derived from the tests of prestressing steel to GB/T 5224 (Grade 1770) are well calibrated. Prestressing steels to ASTM A421 (Grade 1725) and GB/T 5224 (Grade 1770) are similar in resistance to thermal creep, while those to ASTM A416 (Grade 1860) and BS 5896 (Grade 1860) are much more resistant to thermal creep than that to GB/T 5224 (Grade 1770). Even though the characteristic strengths are similar, the thermal creep behaviour can be very different in view of differences in chemical composition, heat treatment, etc. Table 1 shows the variations of chemical composition of prestressing steel to various standards (Gales et al. 2012), but that for GB/T 5224 (Grade 1860) is unavailable. Therefore, attention should be paid to the proper choice of thermal creep parameters when such effects of prestressing steel are taken into account in numerical analysis. 


\subsection{Modelling of Isothermal Relaxation}

The numerical predictions of thermal relaxation of prestressing steel are then compared with the test results of and Zhang and Zheng (2006) and Atienza and Elices (2009). Model-1 and Model-2 are used in conjunction with the four sets of thermal creep parameters described above for various stress ranges.

\subsubsection{Validation against test results of Zhang and Zheng (2006)}

In the isothermal relaxation tests conducted by Zhang and Zheng (2006) on the same kind of prestressing steel as that in the thermal creep tests, the gauge length measured by extensometer was kept constant, while the measurements of relaxation or loss of prestress with respect to time were recorded. The finite element mesh in Section 4.1 is used. The relaxation values predicted by the numerical model under the test conditions are compared with those obtained from tests as shown in Figure 6, with different sets of thermal creep parameters adopted approximately within their applicable stress ranges. As expected, both the numerical and test results show the rate of relaxation to reduce with time.

Specifically in Figure 6(a), the relaxation values under initial stress of 250MPa predicted by the thermal creep parameters of ASTM A421 (Grade 1725) are consistent with those obtained from tests at elevated temperatures of $400^{\circ} \mathrm{C}$ and $500^{\circ} \mathrm{C}$. Under the initial stress of $501 \mathrm{MPa}$ as shown in Figure 6(b), predictions of relaxation using the thermal creep parameters of ASTM A421 (Grade 1725) and GB/T 5224 (Grade 1770) agree well with the test results, except that Model-1 predicts less relaxation at the temperature of $300^{\circ} \mathrm{C}$. In Figure 6(c), the predictions of relaxation using the thermal creep parameters of GB/T 5224 (Grade 1770) agree well with the test results at the temperature of $300^{\circ} \mathrm{C}$, but they tend to overestimate at the temperature of $400^{\circ} \mathrm{C}$. The relatively large discrepancies are possibly caused by tertiary creep that develops quickly at high stress and temperature, which the numerical model does not account for. The predictions of relaxation under the initial stress of 1002 MPa using various sets of thermal creep parameters as shown in Figure 6(d) indicate that GB/T 5224 (Grade 1770) overestimates relaxation and ASTM A416 (Grade 1860) underestimates relaxation especially at the temperature of $250^{\circ} \mathrm{C}$, while BS 5896 (Grade 1860) significantly underestimates relaxation. The underestimation of relaxation is caused by the relatively small thermal creep strain predicted by the thermal creep parameters of ASTM A416 (Grade 1860) and BS 5896 (Grade 1860). The predictions based on Model-1 and Mode-2 using the four sets of thermal creep parameters under the different initial stresses and temperatures have essentially the same trend with time in spite of some 
discrepancies. In particular, they both give reasonable predictions compared with tests results when the thermal creep parameters of GB/T 5224 (Grade 1770) are used.

\subsubsection{Validation against results of Atienza and Elices (2009)}

Atienza and Elices (2009) conducted stress relaxation tests of commercial prestressing steel wires at elevated temperatures. The prestressing steel wire had a mean strength of 1950 MPa and a mean "yield" strength of $1770 \mathrm{MPa}$ at ambient temperature. The total tested length of steel wire between grips was $1.2 \mathrm{~m}$, but the heated length was not specified. The heated length has been estimated to be $400 \mathrm{~mm}$ using a picture of the test setup. The relaxation of prestressing steel wire was assumed to begin once the target temperature of the heated length was reached and the target initial stress was applied. During the test, the total tested length of steel wire was kept constant. Outside the heated length, the air temperature is taken to be ambient for heat transfer analysis. To model a $1.2 \mathrm{~m}$ length of wire of $5 \mathrm{~mm}$ diameter, 960 solid elements are used. The losses of prestress are also predicted by Model-1 and Model-2 with the four sets of thermal creep parameters in accordance with their applicable stress ranges. Figure 7 shows the numerical results compared with available test results.

Similarly, the loss of prestress increases dramatically at the onset and then gradually slows down under various initial stresses and at different elevated temperatures. Figure 7(a) for initial stress of 585 MPa shows that the predicted losses of prestress using the thermal creep parameters of ASTM A416 (Grade 1860) are higher than the test results at the temperature of $500^{\circ} \mathrm{C}$, while at the temperature of $400^{\circ} \mathrm{C}$, the predicted results are slightly below the test results, but at the temperature of $300^{\circ} \mathrm{C}$, the predicted results are much smaller than the test results. On the other hand, the results predicted by BS 5896 (Grade 1860) are far too small. In Figure 7(b), GB/T 5224 (Grade 1770) and ASTM A421 (Grade 1860) both give similar predictions under the initial stress of $585 \mathrm{MPa}$ at various elevated temperatures. While the predicted results are much larger than the test results at the temperatures of $500^{\circ} \mathrm{C}$ and $400^{\circ} \mathrm{C}$, they are slightly smaller and closer to the test results at the temperature of $300^{\circ} \mathrm{C}$. Under the initial stress of $975 \mathrm{MPa}$ as shown in Figure 7(c), the predicted losses of prestress by ASTM A416 (Grade 1860) are consistent with test results, while those by GB/T 5224 (Grade 1770) are larger and those by BS 5896 (Grade 1860) are much smaller than the test results. When the initial stress is $1365 \mathrm{MPa}$, Figure 7(d) shows that the predicted losses of prestress by ASTM A416 (Grade 1860) and to a smaller extent BS 5896 (Grade 1860) are quite consistent with the test 
results at the temperature of $300^{\circ} \mathrm{C}$, but at the temperature of $200^{\circ} \mathrm{C}$, all the predicted results by ASTM A416 (Grade 1860) and BS 5896 (Grade 1860) are much smaller than the test results. Therefore, all these results suggest that the thermal creep properties of ASTM A416 (Grade 1860) can predict relatively well the relaxation effects in the tests conducted by Atienza and Elices (2009).

\subsubsection{Discussions}

The specimens tested by Zhang and Zheng (2006) were prestressing steel to GB/T 5224 (Grade 1770). In the tests of Atienza and Elices (2009), the specimens were Spanish commercial prestressing steel without the grade specified, but the actual yield strength and ultimate strength at ambient temperature were given. The former specimens had lower strengths compared with the latter. Moreover, the test procedures were slightly different. Zhang and Zheng (2006) kept the gauge length measured by the extensometer constant during the test, which is strictly the true relaxation at the test temperature. However, Atienza and Elices kept the length between grips constant, which comprised the heated length and that at ambient temperature. In numerical modelling, the thermal creep parameters of GB/T 5224 (Grade 1770) can better predict the thermal relaxation in the tests conducted by Zhang and Zheng (2006), while those of ASTM A416 (Grade 1860) perform better with the results obtained by Atienza and Alices except for relatively low temperatures (e.g. $200^{\circ} \mathrm{C}$ ). The thermal relaxation and creep strains predicted by Model-1 and Model-2 are very close at high temperatures (e.g. $400^{\circ} \mathrm{C}$ ), but there are more discrepancies at relatively low temperatures (e.g. $300^{\circ} \mathrm{C}$ ). Actually Model-2 predicts slightly higher thermal creep strain than Model-1 during primary creep, which is obvious and accounts for most of the thermal creep strain in the first 2 hours at relatively low temperatures, but thermal creep is less significant at high temperatures. Hereafter, only Model-1 is adopted for numerical modelling.

\subsection{Modelling of Transient Relaxation}

\subsubsection{Validation against MacLean's tests}

The proposed numerical model should also apply to thermal relaxation under transient heating-cooling conditions. MacLean (2007) conducted thermal relaxation tests of prestressing steel strands adopting certain heating-soaking-cooling regimes. A schematic diagram of the regime is illustrated in Figure 8 using the specific temperature curves given by MacLean (2007). To model a $5.4 \mathrm{~m}$ length of tendon of $13 \mathrm{~mm}$ diameter, 1432 solid elements are used. Figures 9 and 10 show its validation against the tests carried out by 
MacLean (2007). Soaking was held for 90 min in most cases after the soaking temperatures (e.g. $400^{\circ} \mathrm{C}$ ) was reached at a heating rate of $10^{\circ} \mathrm{C} / \mathrm{min}$. Moreover, tests with soaking durations of $5 \mathrm{~min}$ and $45 \mathrm{~min}$ were also investigated with soaking temperature of $400^{\circ} \mathrm{C}$. The specimens used were Grade 1860 low relaxation 7-wire steel strands with a diameter of $13 \mathrm{~mm}$ to ASTM A416, having an effective total length of $5.4 \mathrm{~m}$ and heated length of $0.61 \mathrm{~m}$. The mechanical properties obtained at ambient conditions include the elastic modulus of 204 GPa, "yield” strength 1843 MPa (0.2\% proof stress) and ultimate strength 2020 MPa.

Model-1 is adopted for validation with the thermal creep parameters of ASTM A416 (Grade 1860) and GB/T 5224 (Grade 1770). Figure 9(a) shows that the predictions of thermal relaxation based on ASTM A416 (Grade 1860) agree well with the test results with slightly higher predicted stresses at the end of test, i.e. $1.8 \%$ higher for $300^{\circ} \mathrm{C}$ and $5.1 \%$ higher for $400^{\circ} \mathrm{C}$. The model predicts premature ruptures at about $474^{\circ} \mathrm{C}$ based on ASTM A416 (Grade 1860), which is obviously conservative compared with tests results. However, modelling based on the thermal creep parameters of GB/T 5224 (Grade 1770) can well capture the development of thermal relaxation for different regimes. Although large discrepancies of $17.6 \%$ and $32 \%$ are obtained at the end of tests for the soaking temperatures of $400^{\circ} \mathrm{C}$ and $500^{\circ} \mathrm{C}$ respectively due to the large thermal creep strain predicted, relatively good agreement is observed for other soaking temperatures. The calculated thermal creep strains of the heated region in Figure 9(b) show that the thermal creep strains based on ASTM A416 (Grade 1860) are much lower than those based on GB/T 5224 (Grade 1770) at temperatures above $300^{\circ} \mathrm{C}$. At relatively lower temperatures (e.g. $200^{\circ} \mathrm{C}$ ), the thermal creep strains are negligible. Besides, when the temperature exceeds $300^{\circ} \mathrm{C}$, thermal creep develops dramatically until rupture occurs or when the stress reduces to a relatively small value, and afterwards it slows down gradually while cooling to ambient temperature.

To investigate the effects of soaking durations on the thermal relaxation of prestressing strands, tests at the soaking temperature of $400^{\circ} \mathrm{C}$ with soaking durations of $5 \mathrm{~min}, 45 \mathrm{~min}$ and $90 \mathrm{~min}$ were conducted by MacLean (2007). Numerical predictions are also obtained based on the thermal creep parameters of ASTM A416 (Grade 1860) accordingly. Figure 10(a) shows good agreement between the numerical and test results, but the predicted stresses are $6.4 \%, 3.3 \%$ and $5.7 \%$ higher than the test results at the end of test for soaking durations of $5 \mathrm{~min}, 45 \mathrm{~min}$ and $90 \mathrm{~min}$, respectively. The corresponding thermal creep strains of the heated region are obtained as shown in Figure 10(b), indicating that the thermal creep strains increase dramatically 
during the initial 30 min but slow down gradually during soaking. Obviously, the longer the soaking duration is, the larger will be the thermal creep strain and loss of prestress as shown in Figure 10(a). Previous analyses confirm the thermal creep strains to be significant for temperatures above $300^{\circ} \mathrm{C}$. To examine the effects of thermal creep strains on thermal relaxation, Figure 11 shows the numerical results obtained for various soaking temperatures without considering thermal creep and those obtained based on Eurocode 2 that accounts for thermal creep implicitly. Figure 11 shows that predictions from Eurocode 2 are consistent with the test results, but it cannot capture the time-dependent variation of stresses induced by creep. The stresses at the end of tests predicted by Eurocode 2 are always above the test results. The numerical model ignoring thermal creep predicts accurately as compared to the test results for the soaking temperature of $200^{\circ} \mathrm{C}$, but the predicted stresses are slightly higher than the test results for the soaking temperature of $300^{\circ} \mathrm{C}$. For soaking temperatures of $400^{\circ} \mathrm{C}, 500^{\circ} \mathrm{C}$ and $700^{\circ} \mathrm{C}$, the numerical model ignoring thermal creep predicts premature rupture in the initial heating phase at the temperatures of $400^{\circ} \mathrm{C}, 451^{\circ} \mathrm{C}$ and $455^{\circ} \mathrm{C}$, respectively, which obviously contradict the test results. Implicit consideration of thermal creep strain in Eurocode 2 works better but it may not always be conservative. Therefore it is better to consider thermal creep explicitly.

\subsubsection{Validation against Gales’ tests}

Continuing the tests of MacLean, Gales (2009) examined prestressing strands with a parabolic profile and a realistic length of $18.6 \mathrm{~m}$. The heated length ratio was reduced to about 3\% to simulate local fire exposure of prestressing strands due to concrete cover spalling. The heating-soaking-cooling regime of MacLean was also adopted, with the same soaking temperatures and nearly the same initial stresses. Besides, tests with lower initial stresses and various heating rates were carried out as well. The proposed numerical model is used to predict the transient behaviour of the prestressing strands tested by Gales. To model an $18.6 \mathrm{~m}$ length of tendon of $13 \mathrm{~mm}$ diameter, 2976 solid elements are used. Figure 12 compares the numerical and experimental results for various soaking temperatures and initial stresses.

The stress variations of prestressing strands under various soaking temperatures in Figure 12(a) indicate that the numerical model based on the thermal creep parameters of ASTM A416 (Grade 1860) can give accurate predictions. In contrast, the numerical model based on the thermal creep parameters of GB/T 5224 (Grade 1770) can accurately predict the transient relaxation at relatively low temperatures (e.g. $300^{\circ} \mathrm{C}$ ) and 
initial stresses (e.g. $600 \mathrm{MPa}$ ), but large discrepancies result for the case with soaking temperature of $400^{\circ} \mathrm{C}$ under the initial stress of about $1000 \mathrm{MPa}$. Based on both sets of thermal creep parameters, Figure 12(b) shows the development of thermal creep strains of the heated region under the initial stress of about 1000 MPa, indicating that the thermal creep strains are negligible at the temperature of $200^{\circ} \mathrm{C}$, observable at $300^{\circ} \mathrm{C}$, and dramatic at $400^{\circ} \mathrm{C}$. It also explains the large loss of prestress under the soaking temperature of $400^{\circ} \mathrm{C}$. Besides, for the lower initial stress of $600 \mathrm{MPa}$, the thermal creep strain is much reduced.

\subsubsection{Discussions}

From validations against the tests conducted by MacLean (2007) and Gales (2009), the proposed numerical model can accurately predict the stress relaxation of prestressing strands under transient heating conditions. Using the thermal creep parameters of GB/T 5224 (Grade 1770), the model can accurately predict the stress relaxation under lower temperatures (e.g. $300^{\circ} \mathrm{C}$ ) or lower initial stresses (e.g. 600MPa). However, using the thermal creep parameters of ASTM A416 (Grade 1860), the model also can accurately predict the stress relaxation under relatively higher temperatures (e.g. $400^{\circ} \mathrm{C}$ ) or higher initial stress (e.g. 1000MPa). Moreover, the model based on ASTM A416 (Grade 1860) also mistakenly and conservatively predicts premature rupture when the temperature reaches $480^{\circ} \mathrm{C}$ under the initial stress of $1000 \mathrm{MPa}$.

In summary, the proposed numerical model can accurately predict the behaviour of the prestressing steel during and after elevated temperatures based on suitable thermal creep parameters. The thermal creep parameters of ASTM A416 (Grade 1860) are considered more suitable for further parametric studies based on the tests conducted by MacLean. Extrapolation outside its applicable stress range will be carried out as necessary.

\section{PARAMETRIC STUDIES}

In the transient thermal relaxation tests conducted by MacLean (2007), the effects of the various soaking temperatures as well as various durations at soaking temperature of $400^{\circ} \mathrm{C}$ on the losses of prestress were investigated. In addition, the effects of other parameters including initial stress, heating rate (accounting for concrete cover), and heated length ratio have been studied by Gales et al. (2009) under standard fire condition (ASTM 119) by the simplified model. The effects of these parameters will be studied by the proposed numerical model based on MacLean's tests with soaking temperatures of $400^{\circ} \mathrm{C}$ and $500^{\circ} \mathrm{C}$ 
adopting the same heating-soaking-cooling regime and the finite element mesh described in Section 4.3.1. Moreover, the effects of boundary condition on the behaviour of prestressing strands will also be studied. In the parametric studies, the thermal creep strains of heated region for the soaking temperature of $400^{\circ} \mathrm{C}$ will be examined to better understand the mechanism of loss of prestress.

\subsection{Initial Stress}

The effects of initial stress on the behaviour of prestressing strands during and after elevated temperatures are studied. The initial stress ranges from $600 \mathrm{MPa}$ to $1600 \mathrm{MPa}$, corresponding to about $30 \%$ and $80 \%$ of the ultimate strength respectively. Figure 13(a) shows the variations of stress for soaking temperatures of $400^{\circ} \mathrm{C}$ and $500^{\circ} \mathrm{C}$, while the thermal creep strains for the soaking temperature of $400^{\circ} \mathrm{C}$ in particular are shown in Figure 13(b). Figure 13(a) shows that, under the soaking temperature of $400^{\circ} \mathrm{C}$, the stresses decrease gradually due to restrained thermal expansion at the outset and then drop dramatically due to the thermal creep strain developing rapidly at about $300^{\circ} \mathrm{C}$ during heating as shown in Figure 13(b). According to Figure 13(a), the prestressing strand with initial stress of $1600 \mathrm{MPa}$ ruptures at $344^{\circ} \mathrm{C}$ during heating. When the initial stresses are in the range of 1000 to $1400 \mathrm{MPa}$ under the soaking temperature of $400^{\circ} \mathrm{C}$, all stresses converge to the common curve in Figure 13(a), resulting in the same residual stress of $800 \mathrm{MPa}$ after heating, which is about $43 \%$ of the ultimate strength at ambient temperature. However, for prestressing strands with lower initial stresses of $800 \mathrm{MPa}$ and $600 \mathrm{MPa}$, their stresses do not converge but stabilize at the residual stresses of $725 \mathrm{MPa}$ and $580 \mathrm{MPa}$ after heating, respectively. To sum up, for initial stresses in the range of $1000 \mathrm{MPa}$ to $1400 \mathrm{MPa}$, the prestressing strands after experiencing 90 min soaking at the temperature of $400^{\circ} \mathrm{C}$ will have the same residual stress of $800 \mathrm{MPa}$ after heating, which is independent of initial stresses. This is explained by much higher thermal creep strains for these cases as shown in Figure 13(b).

However, when the soaking temperature rises to $500^{\circ} \mathrm{C}$, the prestressing strands with initial stresses not less than $1000 \mathrm{MPa}$ all rupture at different temperatures during heating as shown in Figure 13(a). Obviously decreasing the initial stress increases the temperature sustained during heating. For initial stresses of 800 MPa and $600 \mathrm{MPa}$, the stresses of prestressing strands similarly converge to a common curve, resulting in almost same residual stress of $390 \mathrm{MPa}$ after heating, which is about $21 \%$ of the ultimate strength at the ambient temperature. 


\subsection{Heating Rate}

Increasing the concrete cover to prestressing strands in PT slabs subjected to fire reduces the heating rate of the strands. The heating rate is selected to range from $5^{\circ} \mathrm{C} / \mathrm{min}$ to $40^{\circ} \mathrm{C} / \mathrm{min}$ to approximately account for the concrete cover from about $40 \mathrm{~mm}$ to $5 \mathrm{~mm}$ when the structure is subjected to standard fire (ISO 834 ).

The variations of stress for soaking temperatures of $400^{\circ} \mathrm{C}$ and $500^{\circ} \mathrm{C}$ are shown in Figure $14(\mathrm{a})$, while the thermal creep strains of the heated region under the soaking temperature of $400^{\circ} \mathrm{C}$ are shown in Figure 14(b). Figure 14(a) shows that the stress losses of strands under soaking temperature of $400^{\circ} \mathrm{C}$ are lower than those of $500^{\circ} \mathrm{C}$. For cases at different heating rates under the soaking temperature of $400^{\circ} \mathrm{C}$, Figure 14(a) shows that, although the losses of prestress develop differently with time, the minimum stresses and residual stresses are nearly the same. The thermal creep strains as shown in Figure 14(b) start to develop rapidly at the temperature of about $300^{\circ} \mathrm{C}$, and then gradually slow down. These creep strains finally converge to about the same value, which explains why the final stresses are nearly the same. Additionally, during the heating process, a higher heating rate causes not only higher temperature but also larger thermal creep strains.

For those cases under the soaking temperature of $500^{\circ} \mathrm{C}$ at these heating rates, Figure $14(\mathrm{a})$ shows that the stresses decrease slowly up to $300^{\circ} \mathrm{C}$ and then drop dramatically afterwards. With the exception of the prestressing strand at the heating rate of $5^{\circ} \mathrm{C} / \mathrm{min}$, those at other heating rates all rupture at the temperature of about $470^{\circ} \mathrm{C}$. Therefore reducing the heating rate or increasing the concrete cover can avoid premature rupture of prestressing strands and enhance the fire resistance of PT slabs. However, if no rupture occurs in the heating-cooling process, the losses of prestress are nearly independent of the heating rates.

\subsection{Heated Length Ratio}

The investigation of potential effects of heated length ratios is mainly to account for local compartmental fire or local concrete cover spalling, directly exposing part of the prestressing strands to severe fire (Gales 2009). In this study, this ratio ranges from $5 \%$ to $50 \%$ to examine the behaviour of prestressing strands during and after elevated temperature.

The variations of stress for different heated length ratios under the soaking temperatures of $400^{\circ} \mathrm{C}$ and $500^{\circ} \mathrm{C}$, are shown in Figure 15(a), while the thermal creep strains of the heated region under the soaking temperature of $400^{\circ} \mathrm{C}$ are shown in Figure 15(b). Figure 15(a) shows that, under the soaking temperature of 
$400^{\circ} \mathrm{C}$, the larger the heated length ratio is, the higher the loss of prestress is during the heating process, but the lower the thermal creep strain of heated region is as shown in Figure 15(b). Especially, it is worth noting that the thermal creep strain of heated region with the heated length ratio of $5 \%$ is much larger than those with other larger ratios. Their residual stresses after cooling are not the same but are reasonably close to one another. When the heated length ratio is small, the expansion caused by heating is minimal giving rise to very high thermal creep strains under comparatively high stress, but the residual stress after cooling is not much lower because of the relatively low loss of elastic extension due to creep. When the heated length ratio is big, the expansion caused by heating is big thereby substantially reducing both the stress and thermal creep strain, and hence the residual stress after cooling is not much lower because of the relatively low loss of elastic extension due to creep. For intermediate values of heated length ratio, the permanent losses of stress are therefore higher in comparison.

Under the soaking temperature of $500^{\circ} \mathrm{C}$, the prestressing strands with heated length ratios of $5 \%$ and $11.3 \%$ both rupture at $403^{\circ} \mathrm{C}$ and $480^{\circ} \mathrm{C}$, respectively as shown in Figure $15(\mathrm{a})$. However, the stresses of those with heated length ratios of $25 \%$ and $50 \%$ continuously decrease during heating without violating the temperature-dependent maximum strength. In this sense, decreasing the heated length ratio will increase the risks of rupture during heating. Therefore the spalling of local concrete cover may directly expose prestressing strands to fire, possibly causing rupture of prestressing strands or even structural collapse. Therefore, it is essential to prevent concrete spalling in fire, especially the concrete cover to prestressing strands.

\subsection{Boundary Conditions}

In the tests conducted by MacLean (2007), the two ends of the prestressing strands are fixed, thereby keeping the total length of strands constant. However, the ends are rarely perfect fixities in practical cases. To investigate the effects of partial fixity, the setup previously used by Au and Si (2011) as shown in Figure 16 is adopted, where $l_{e}$ denotes the length of the strand; $K$ denotes the axial stiffness of the strand at ambient temperature and $K_{S}$ denotes the stiffness of perfect elastic spring independent of temperature. The effects of various boundary conditions can be studied by changing the value of $K_{S}$.

The potential effects of various boundary conditions are investigated based on the MacLean's tests for the soaking temperatures of $400^{\circ} \mathrm{C}$ and $500^{\circ} \mathrm{C}$ under an initial stress of $1000 \mathrm{MPa}$ applied to the system. The 
stiffness of the perfectly elastic spring varies from $2 K$ to infinity, which correspond to partial and perfect fixity. The losses of prestress and thermal creep strains of the heated region for various boundary conditions are shown in Figure 17. Figure 17(a) shows the variations of stress for soaking temperatures of $400^{\circ} \mathrm{C}$ and $500^{\circ} \mathrm{C}$ under various boundary conditions. For the soaking temperature of $400^{\circ} \mathrm{C}$, no rupture occurs, and the variations of stress broadly follow the same trend, with the residual stresses after cooling being about $800 \mathrm{MPa}$. Although there are obvious differences in the thermal creep strain as shown in Figure 17(b), there is little difference in the loss of elastic extension because of the relatively small heated length ratio. For cases with soaking temperature of $500^{\circ} \mathrm{C}$, rupture occurs during heating at the temperatures of $445^{\circ} \mathrm{C}$, $470^{\circ} \mathrm{C}, 480^{\circ} \mathrm{C}$ and $481^{\circ} \mathrm{C}$, for values of elastic stiffness of $2 \mathrm{~K}, 10 \mathrm{~K}, 100 \mathrm{~K}$ and infinity, respectively.

\subsection{Discussions}

The parametric studies of initial stress, heating rate, heated length ratio and boundary condition provide better understanding of the behaviour of prestressing strands under transient heating-cooling conditions. Investigation of the effects of initial stresses on the prestressing strands experiencing the same heatingcooling process shows that, except for those with early rupture during heating, their stress variations especially for those with higher initial stresses tend to converge to common curves so that the residual stresses are nearly independent of the initial stresses. This is consistent with the findings in the tests of prestressing strands under standard fire conditions (ASTM E119) by Gales et al. (2009). This phenomenon is essentially governed by the thermal creep characteristics. With the gradual decrease of stress at elevated temperature, thermal creep also becomes slower and vice versa.

The thermal relaxation develops faster at higher heating rate, but the minimum and residual stresses are almost independent of the heating rate, as confirmed by the tests conducted by Gales et al. (2009) for the maximum temperature of $400^{\circ} \mathrm{C}$. However, if the temperature exceeds $400^{\circ} \mathrm{C}$, a higher heating rate will cause earlier rupture of prestressing strands, possibly leading to structural failure. Obviously, reducing the heating rate benefits the fire resistance of PT concrete slabs by reducing the chance of tendon rupture, but its effects on the residual tendon stresses are minimal.

A higher heated length ratio gives higher loss of prestress during the heating process, but lower thermal creep strain in the heated region. Results indicate that the thermal elongation strain dominates the relaxation behaviour of prestressing strands with higher heated length ratio, while the thermal creep strain 
dominates the relaxation behaviour with lower heated length ratio. This is also consistent with the numerical findings by Gales et al. (2009). Moreover, a low heated length ratio may cause early rupture of prestressing strands. It therefore implies that concrete spalling may bring about early failure of PT concrete slabs due to the rupture of prestressing strands.

Variation of boundary condition has little effect on the losses of prestress, but significant effect on the thermal creep strains of the heated region and the temperature at which rupture occurs for those subject to higher peak temperature. In particular, a smaller end support stiffness causes larger thermal creep strains and possibly early rupture of prestressing strands.

\section{TRANSIENT STATE ANALYSIS}

Transient state analysis is further conducted to investigate the rupture properties of prestressing steel based on the numerical model. In this section, prestressing steel to GB/T 5224 (Grade 1770) is used, assuming the mechanical properties of the test specimens used by Zhang and Zheng (2006) as shown in Section 4.1. In the numerical modelling, the prestressing steel sample with length of $1 \mathrm{~m}$ and diameter of $5 \mathrm{~mm}$ is modelled by 800 solid elements. The heated length at the central part of sample is $250 \mathrm{~mm}$. In the transient state analysis, the initial stress and heating rate are kept constant until rupture occurs.

The effects of initial stresses of $1000 \mathrm{MPa}$ and $600 \mathrm{MPa}$ and heating rates of $2^{\circ} \mathrm{C} / \mathrm{min}$ and $5^{\circ} \mathrm{C} / \mathrm{min}$ on the rupture of prestressing steel are investigated. The effects of thermal creep are taken into account using the thermal creep parameters to GB/T 5224 (Grade 1770) and ASTM A416 (Grade 1860). Figure 18 shows the variations of total strain and creep strain of the heated region with time under various combinations of initial stresses and heating rates.

Figure 18(a) shows that the prestressing steel samples under the initial stress of $1000 \mathrm{MPa}$ and heating rates of $2^{\circ} \mathrm{C} / \mathrm{min}$ and $5^{\circ} \mathrm{C} / \mathrm{min}$ all rupture at the temperature of about $315^{\circ} \mathrm{C}$ irrespective of the thermal creep parameters used. The prestressing steel samples under the initial stress of $600 \mathrm{MPa}$ and heating rates of $2^{\circ} \mathrm{C}$ $/ \mathrm{min}$ and $5^{\circ} \mathrm{C} / \mathrm{min}$ all rupture at the temperature of about $420^{\circ} \mathrm{C}$ also irrespective of the thermal creep parameters used. The total strains and creep strains of the heated region calculated based on GB/T 5224 (Grade 1770) as shown in Figures 18(a) and 18(b) respectively are higher than those based on ASTM A416 (Grade 1860) and those calculated ignoring thermal creep. The variations of total strains of the heated 
region with time always depend on the thermal creep strains. The temperature at which prestressing steel ruptures depends mainly on the initial stress, but is relatively insensitive to the heating rate and thermal creep properties.

The discrepancies of creep strain may be attributed to differences in chemical composition, heat treatment, etc. However, when high-strength steel is used as tendons in prestressed concrete structures, the scenario of relaxation with the total length kept more or less unchanged will be more relevant than the scenario of creep under constant stress. In the relaxation scenario, a higher creep induces more loss in stress and it tends to reduce further increase in creep. In comparison, the predictions of total strain are more consistent. Prediction of failure, e.g. the temperature during the heating phase, is relatively consistent.

\section{CONCLUSIONS}

The proposed numerical model is shown to be versatile in predicting various behaviour of prestressing steel tendons during or after exposure to elevated temperatures. A new set of parameters of prestressing steel to GB/T 5224 (Grade 1770) for Harmathy’s thermal creep model has been presented with proper calibration against available test results. With suitable choice of thermal creep parameters, the model can accurately predict the stress variations of prestressing steel tendons as well as possible rupture.

Parametric studies indicate that a higher initial stress or heating rate may cause early rupture of prestressing steel tendons. However, except for those with early rupture during heating, their stress variations especially for those with higher initial stresses tend to converge to common curves so that the residual stresses are nearly independent of the initial stresses. The thermal elongation strain dominates the relaxation behaviour of prestressing strands with higher heated length ratio, while the thermal creep strain dominates the relaxation behaviour with lower heated length ratio. A low heated length ratio may also cause early rupture of prestressing strands. Common boundary conditions should have little effect on the relaxation of prestressing steel tendons during or after exposure to elevated temperatures.

Transient state analyses indicate that the temperature at which prestressing steel tendons rupture depends mainly on the initial stress, but is essentially independent of the heating rate and thermal creep properties. Although numerical models with parameters based on specimens to different standards predict thermal creep strains with some discrepancies, the total strains in typical relaxation scenarios found in prestressed 
concrete structures and the predicted failures are more consistent.

\section{ACKNOWLEDGEMENTS}

The work described here has been supported by the Research Grants Council (RGC) of Hong Kong Special Administrative Region, China (RGC Project No.: HKU 710012E) and the State Key Laboratory of Subtropical Building Science of South China University of Technology, China (Project No.: 2011KA02).

\section{REFERENCES}

Atienza, J.M. and Elices, M. (2009). "Behaviour of prestressing steels after a simulated fire: Fire-induced damages”. Construction and Building Materials, Vol. 23, No. 8, pp. 2932-2940.

Au, F.T.K. and Si, X.T. (2011). “Accurate time-dependent analysis of concrete bridges considering concrete creep, concrete shrinkage and cable relaxation”. Engineering Structures, Vol. 33, No. 1, pp. 118-126.

Bailey, C. and Ellobody, E. (2009a). "Fire tests on unbonded post-tensioned one-way concrete slabs". Magazine of Concrete Research, Vol. 61, No. 1, pp. 67-76.

Bailey, C. and Ellobody, E. (2009b). "Fire tests on bonded post-tensioned concrete slabs”. Engineering Structures, Vol. 31, No. 3, pp. 686-696.

Ellobody, E. and Bailey, C.G. (2008). "Modelling of bonded post-tensioned concrete slabs in fire". Proceedings of the Institution of Civil Engineers-Structures and Buildings, Vol. 161, No.2, pp. 311-323.

Ellobody, E. and Bailey, C. (2009). "Modelling of unbonded post-tensioned concrete slabs under fire conditions”. Fire Safety Journal, Vol. 44, No. 2, pp. 159-167.

Ellobody, E. and Bailey, C. (2011). "Structural performance of a post-tensioned concrete floor during horizontally travelling fires”. Engineering Structures, Vol. 33, No. 8, pp. 1908-1917.

Eurocode 1. (2002). Actions on structures - Part 1-2: General actions - Actions on structures exposed to fire. BSI, London.

Eurocode 2. (2004). Design of concrete structures - Part 1-2: General rules - Structural fire design. BSI, London.

Gales, J. (2009). Transient high-temperature prestress relaxation of unbounded Prestressing tendons for use in concrete slabs. M.Sc. Thesis, Department of Civil Engineering, Queen’s University, Kingston, ON, Canada 
Gales, J., Bisby, L., MacDougall, C. and MacLean, K. (2009). “Transient high-temperature stress relaxation of Prestressing tendons in unbounded construction”. Fire Safety Journal, Vol. 44, No. 4, pp. 570-579.

Gales, J., Bisby, L. and Stratford, T. (2012). “High Temperature Creep Deformation and Failure Behaviour of Prestressing Steel”. Proceedings of the $7^{\text {th }}$ International Conference on Structures in Fire, Fontana, M., Frangi, A. and Knobloch, M., eds, Zurich, Switzerland, June, pp. 659-668.

Gao, L.T., Dong, Y.L. and Yuan, A.M. (2004). "Experimental investigation of the behaviours of continuous slabs of unbonded prestressed concrete with the end span under fire”. Journal of Building Structures, Vol. 25, No. 2, pp. 118-123. (In Chinese)

Gustaferro, A.H. (1973). “Fire resistance of post-tensioned structures”. Precast/Prestressed Concrete Institute, Vol. 18, No. 2, pp. 38-63.

Harmathy, T.Z. (1967). A comprehensive creep model. National Research Council of Canada, Division of Building Research, Ottawa.

Harmathy, T.Z. and Stanzak, W.W. (1970). Elevated-Temperature Tensile and Creep Properties of Some Structural and Prestressing Steels. National Research Council of Canada, Division of Building Research, Ottawa.

Hertz, K.D. (2004). “Reinforcement data for fire safety design”. Magazine of Concrete Research, Vol. 56, No. 8, pp. 453-459.

Kodur, V.K.R. and Dwaikat, M.M.S. (2010). "Effect of high temperature creep on the fire response of restrained steel beams”. Materials and Structures, Vol. 43, No. 10, pp. 1327-1341.

MacLean, K. (2007). Post-fire Assessment of Unbonded Post-Tensioned Concrete Slabs: Strand Deterioration and Prestress Loss. M.Sc. Thesis, Department of Civil Engineering, Queen’s University, Kingston, ON, Canada.

Naumenko, K. and Altenbach, H., eds, (2007). Modelling of Creep for Structural Analysis, Springer Berlin Heidelberg, New York, USA.

Poirier, J.P. (1985). Creep of crystals: High-temperature deformation processes in metals, ceramics and minerals. Cambridge University Press, New York, USA.

Wei, Y. and Au, F.T.K. (2011). "Numerical simulation of unbonded post-tensioned concrete slabs under fire”. Proceedings of 3rd International Postgraduate Conference on Infrastructure and Environment, July, Hong Kong, China, Vol. 1, pp. 80-87. 
Yuan, A.M., et al. (2006). "Experimental investigation of unbonded prestressed concrete continuous slab subjected to fire”. Journal of Building Structures, Vol. 27, No. 6, pp. 60-66. (In Chinese)

Zhang, H.Y. and Zheng, W.Z. (2006). “An experimental study on the creep and stress relaxation properties of 1770- $\sim$ P5 prestressing steel wires at high temperatures”. China Civil Engineering Journal, Vol. 39, No. 8, pp. 7-13. (In Chinese)

Zheng, W.Z., Hou, X.M., Shi, D.S. and Xu, M.X. (2010). "Experimental study on concrete spalling in prestressed slabs subjected to fire”. Fire Safety Journal, Vol. 45, No. 5, pp. 283-297.

Zheng, W.Z. and Hou, X.M. (2008). "Experiment and analysis on the mechanical behaviour of PC simplysupported slabs subjected to fire." Advances in Structural Engineering, Vol. 11, No. 1, pp. 71-89. 


\section{List of Figure Captions}

Figure 1. Creep strain under constant stress and temperature

Figure 2. Identification of $\mathrm{Z}$ for different kinds of prestressing steel

Figure 3. Creep strains predicted by numerical models with thermal creep parameters of GB/T 5224 (Grade 1770) and ASTM A421 (Grade 1725) compared to test results (Zhang and Zheng 2006)

Figure 4. Creep strains predicted by numerical model with thermal creep parameters of ASTM A416 (Grade 1860) compared to test results (Zhang and Zheng 2006)

Figure 5. Creep strains predicted by numerical model with thermal creep parameters of BS 5896 (Grade 1860) compared to test results (Zhang and Zheng 2006)

Figure 6. Relaxation predicted by numerical model with various thermal creep parameters compared to test results (Zhang and Zheng 2006)

Figure 7. Relaxation predicted by numerical model with various thermal creep parameters compared to test results (Atienza and Elices 2009)

Figure 8. Heating-soaking-cooling regime

Figure 9. Transient relaxation and creep at various soaking temperatures

Figure 10. Transient relaxation and creep with various soaking time

Figure 11. Transient relaxation predicted with and without consideration of creep

Figure 12. Transient relaxation and creep of tests at various soaking temperatures

Figure 13. Transient relaxation and creep under various initial stresses

Figure 14. Transient relaxation and creep under various heating rates

Figure 15. Transient relaxation and creep for various heated length ratios

Figure 16. Schematic diagram of variation of boundary conditions

Figure 17. Transient relaxation and creep for various boundary conditions

Figure 18. Results of transient state analysis under different initial stresses and heating rates 


\section{List of Table Caption}

Table 1. Chemical composition of various prestressing steel (\%) 


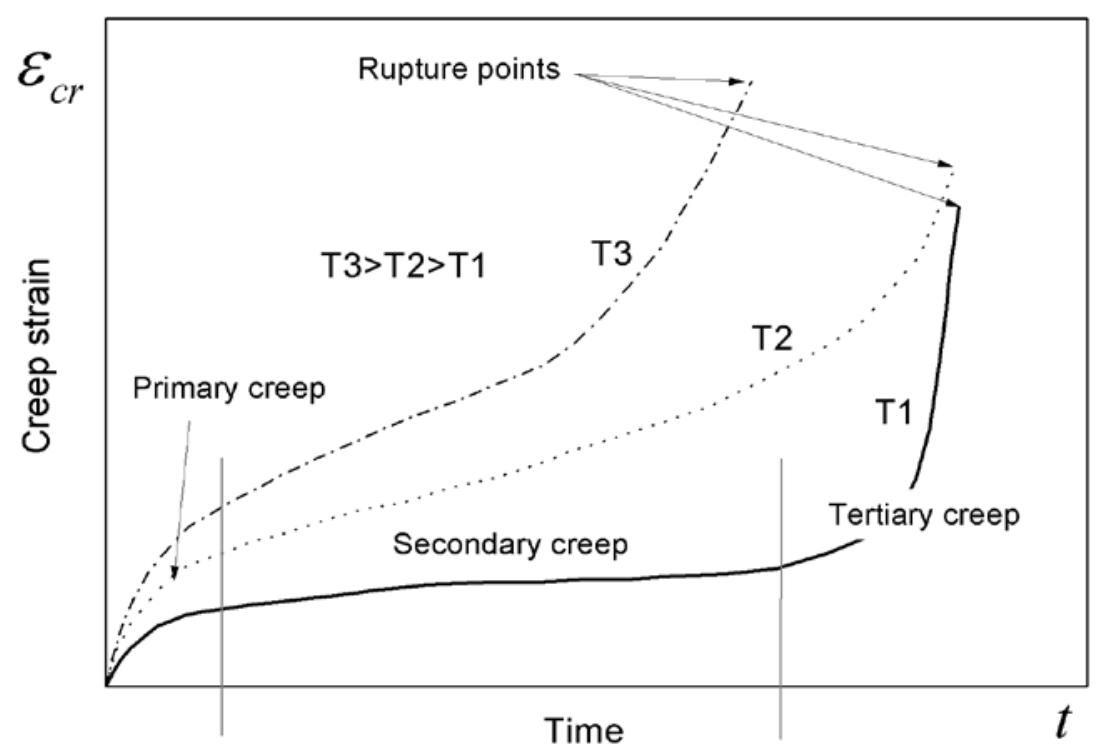

(a) Creep strains at different temperatures

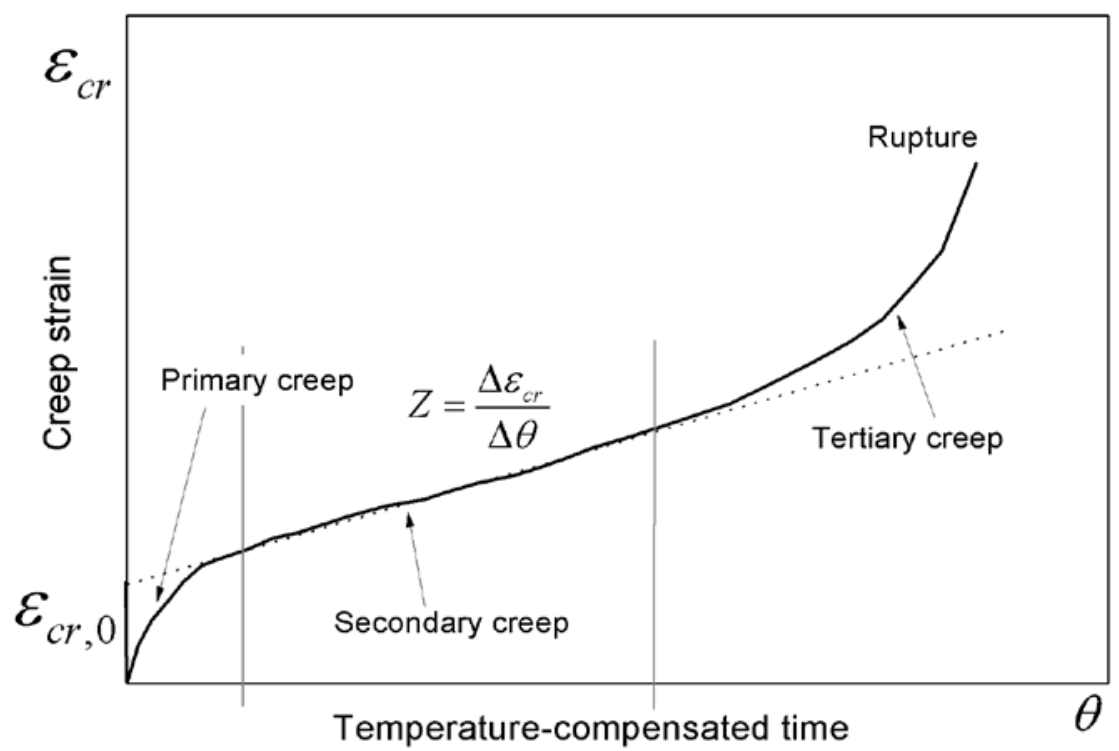

(b) Variation of creep strain with temperature-compensated time

Figure 1. Creep strain under constant stress and temperature 


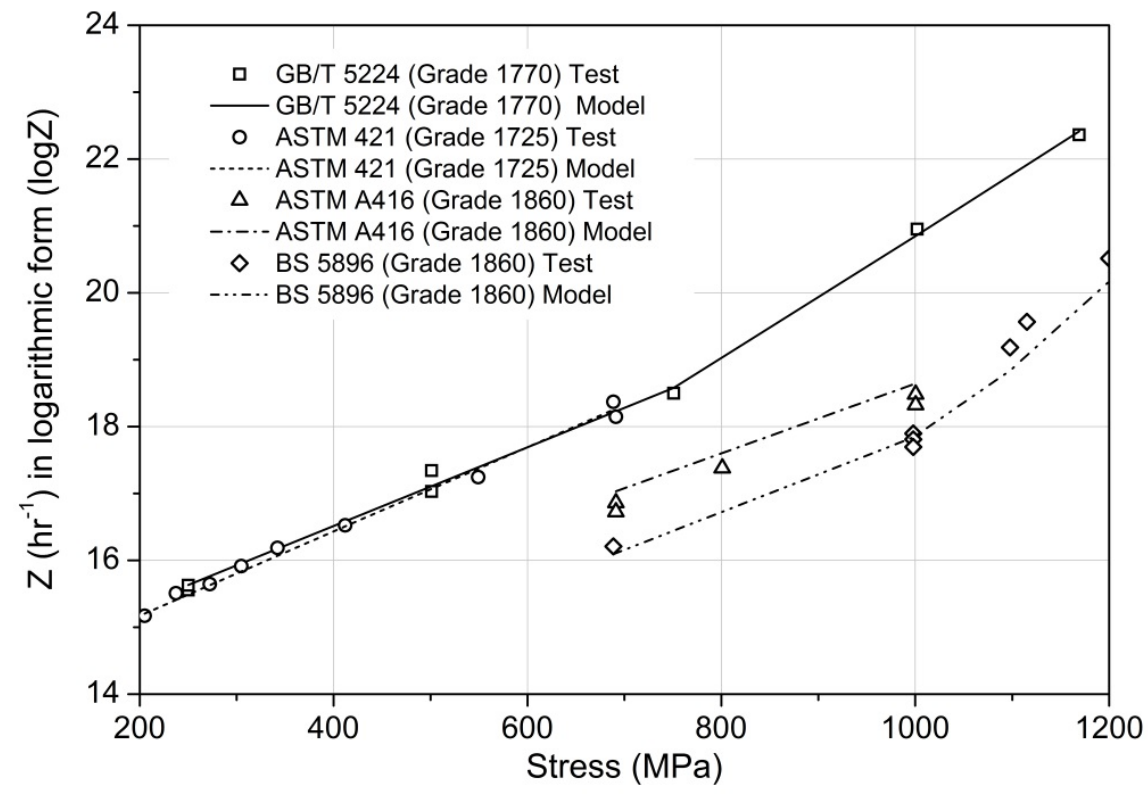

Figure 2. Identification of $Z$ for different kinds of prestressing steel 


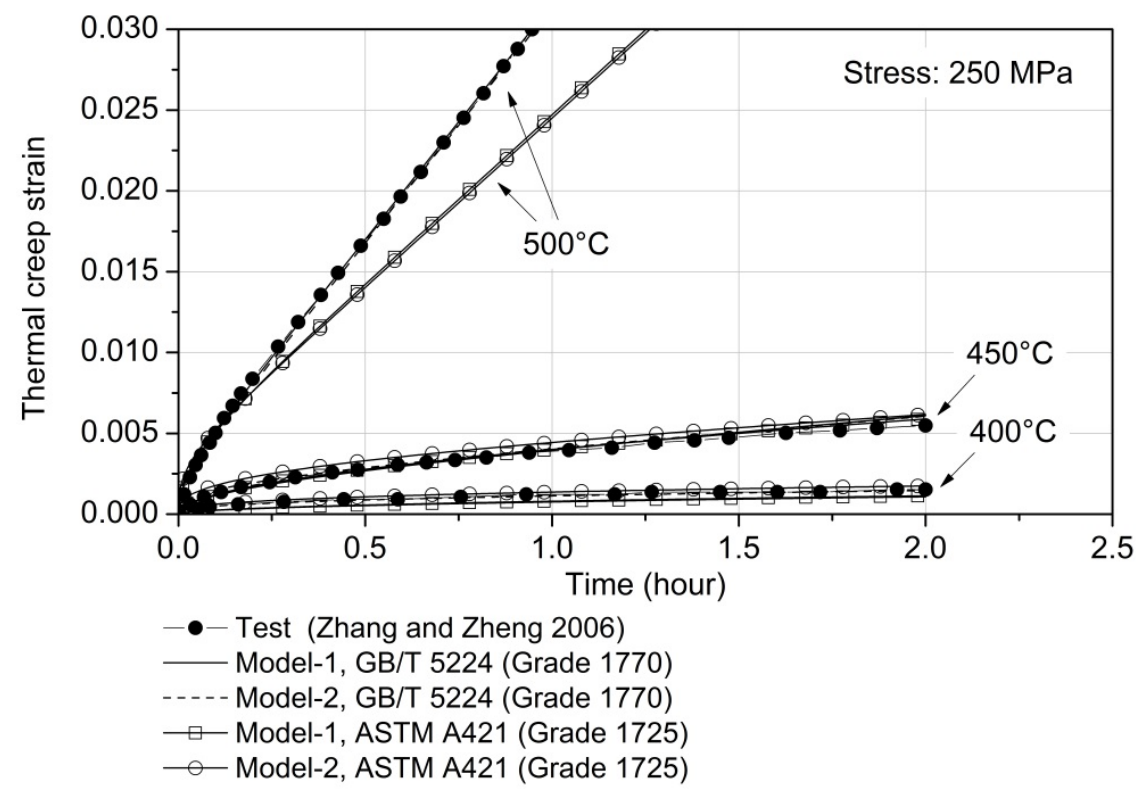

(a) Response under stress of $250 \mathrm{MPa}$

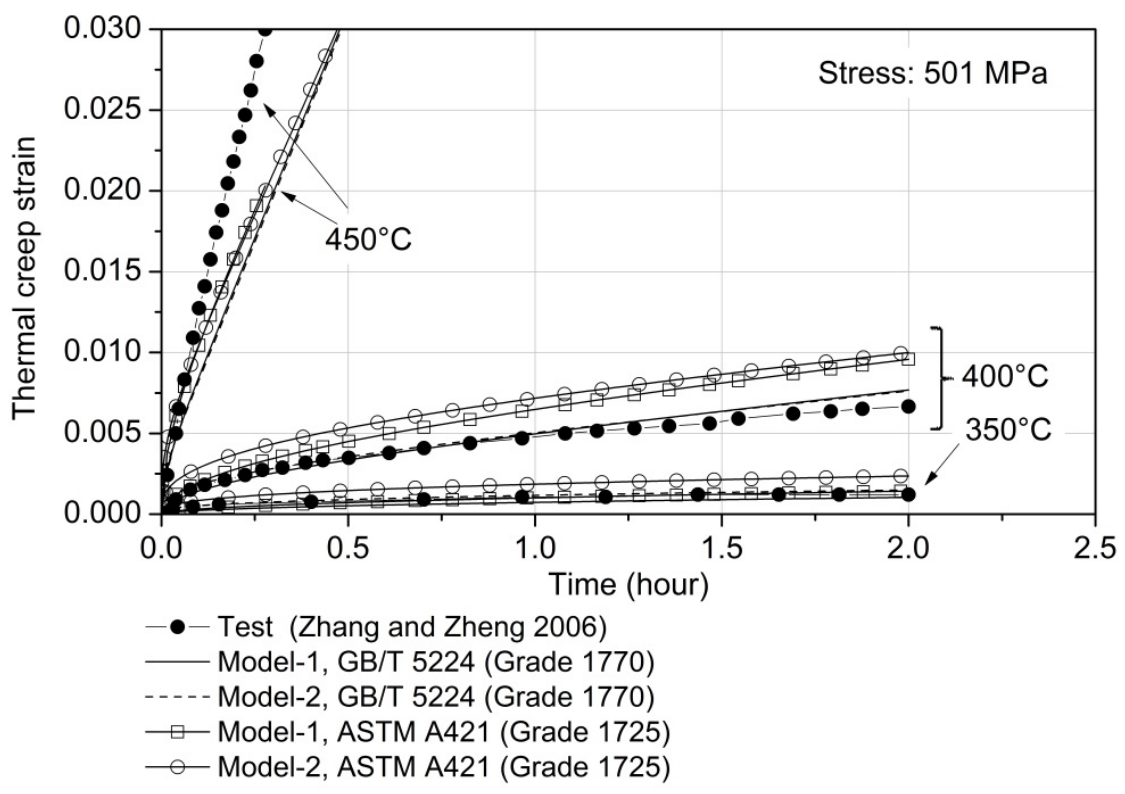

(b) Response under stress of $501 \mathrm{MPa}$

Figure 3. Creep strains predicted by numerical models with thermal creep parameters of GB/T 5224 (Grade 1770) and ASTM A421 (Grade 1725) compared to test results (Zhang and Zheng 2006) 


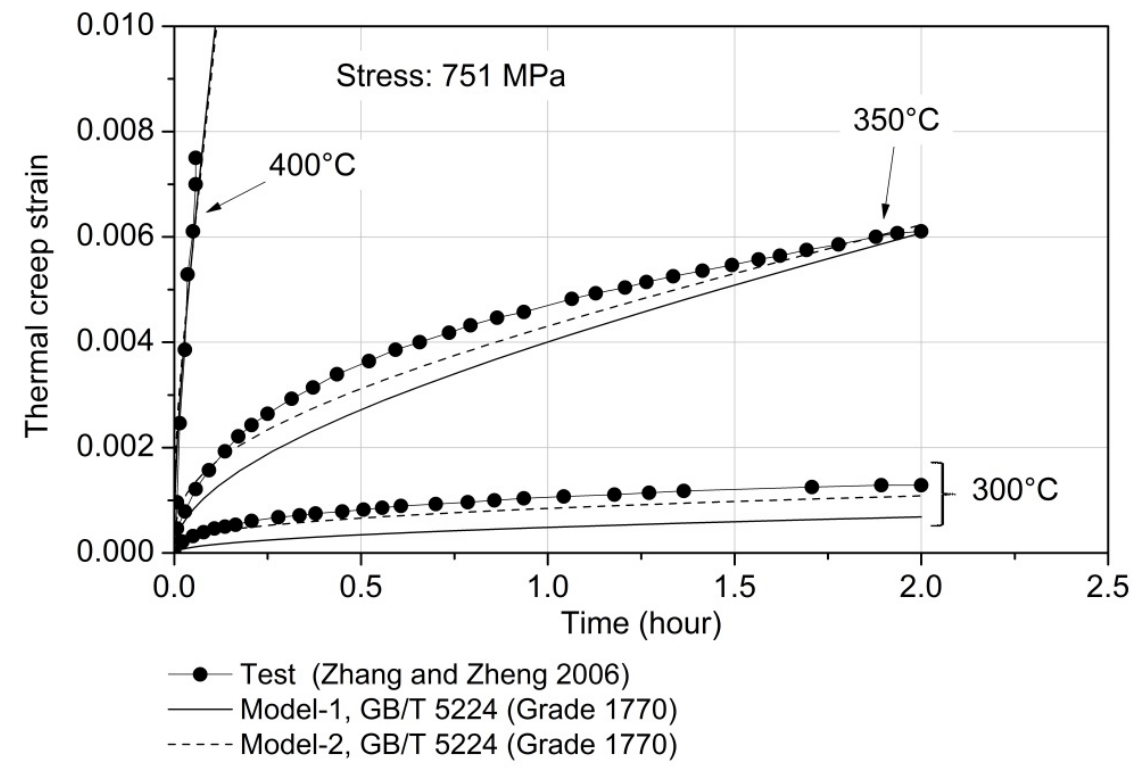

(c) Response under stress of $751 \mathrm{MPa}$

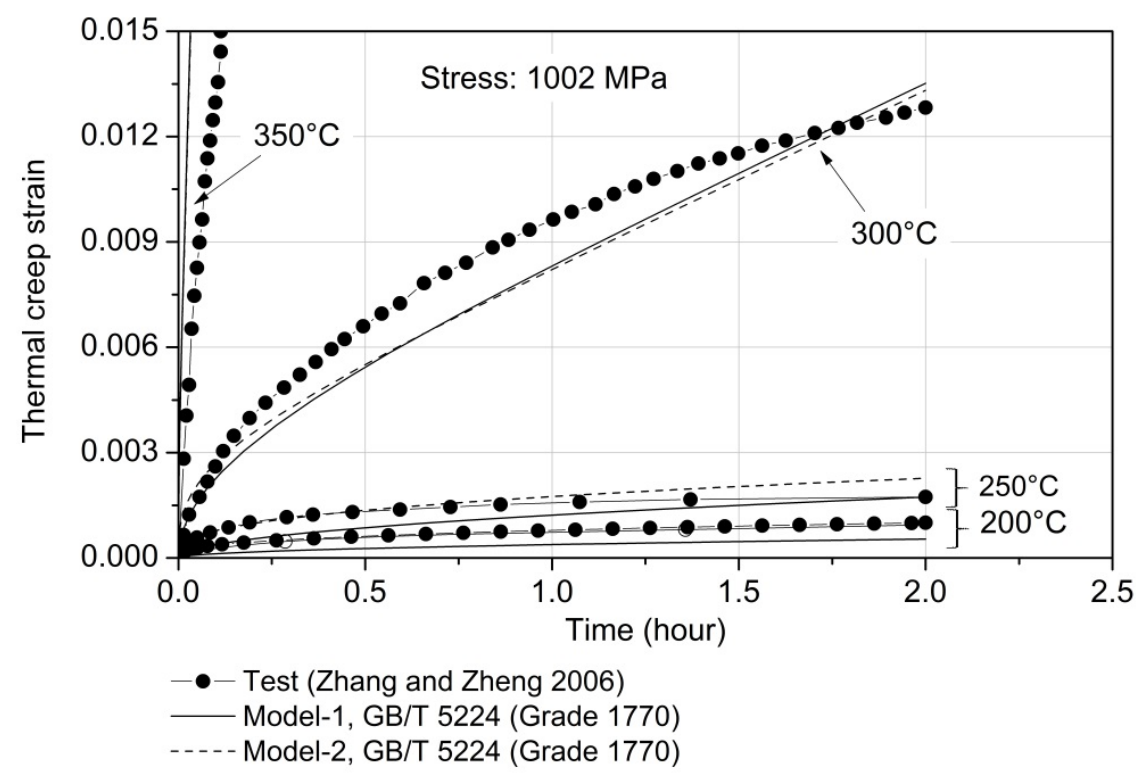

(d) Response under stress of $1002 \mathrm{MPa}$

Figure 3. Creep strains predicted by numerical models with thermal creep parameters of GB/T 5224 (Grade 1770) and ASTM A421 (Grade 1725) compared to test results (Zhang and Zheng 2006) (continued) 


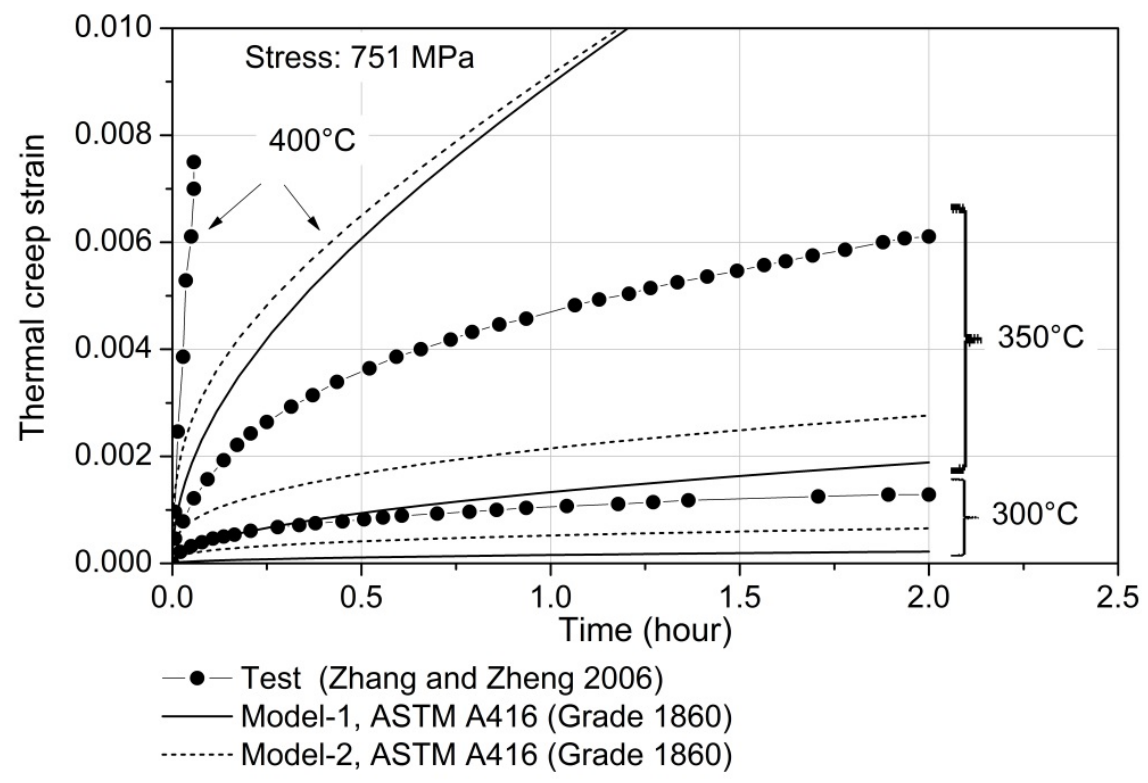

(a) Response under stress of $751 \mathrm{MPa}$

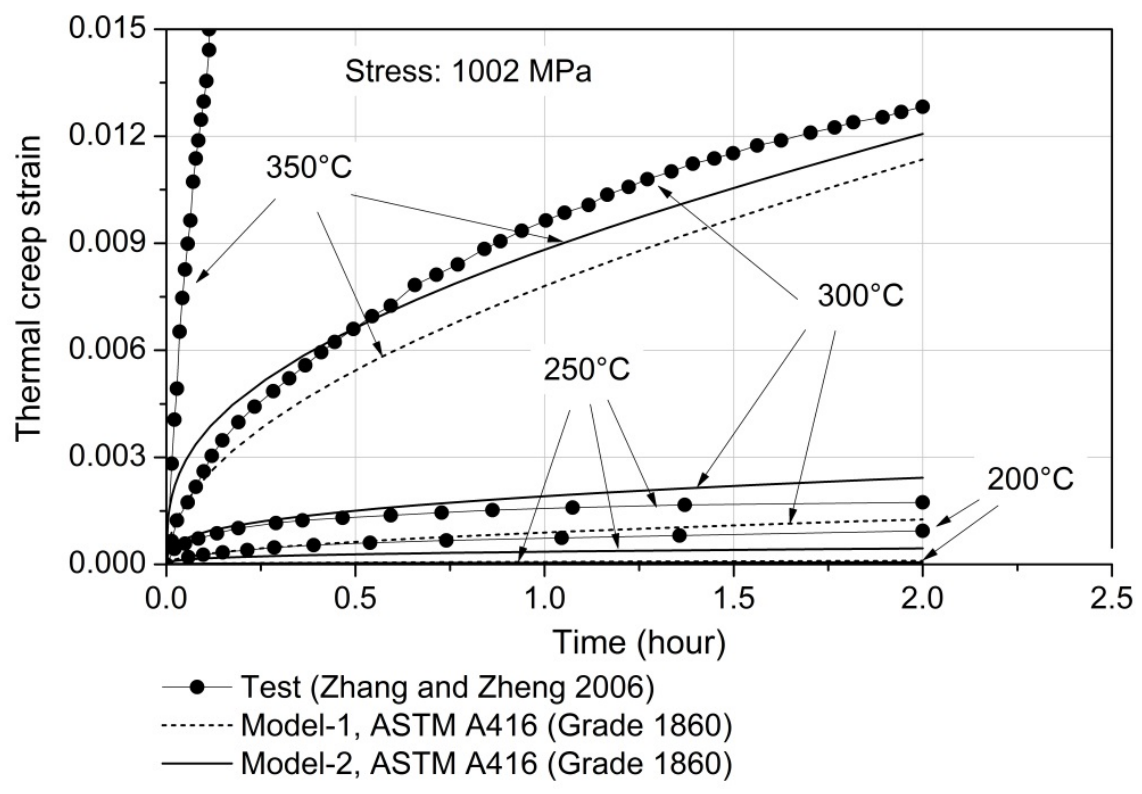

(b) Response under stress of $1002 \mathrm{MPa}$

Figure 4. Creep strains predicted by numerical model with thermal creep parameters of ASTM A416

(Grade 1860) compared to test results (Zhang and Zheng 2006) 


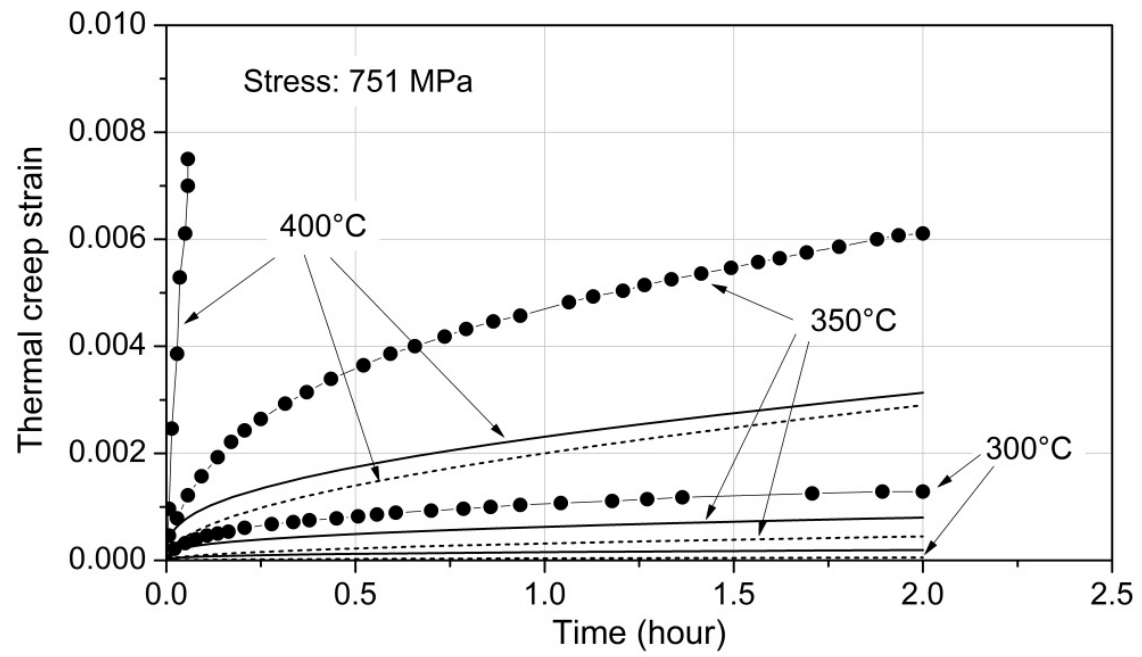

- Test (Zhang and Zheng 2006)

- Model-1, BS 5896 (Grade 1860)

Model-2, BS 5896 (Grade 1860)

(a) Response under stress of $751 \mathrm{MPa}$

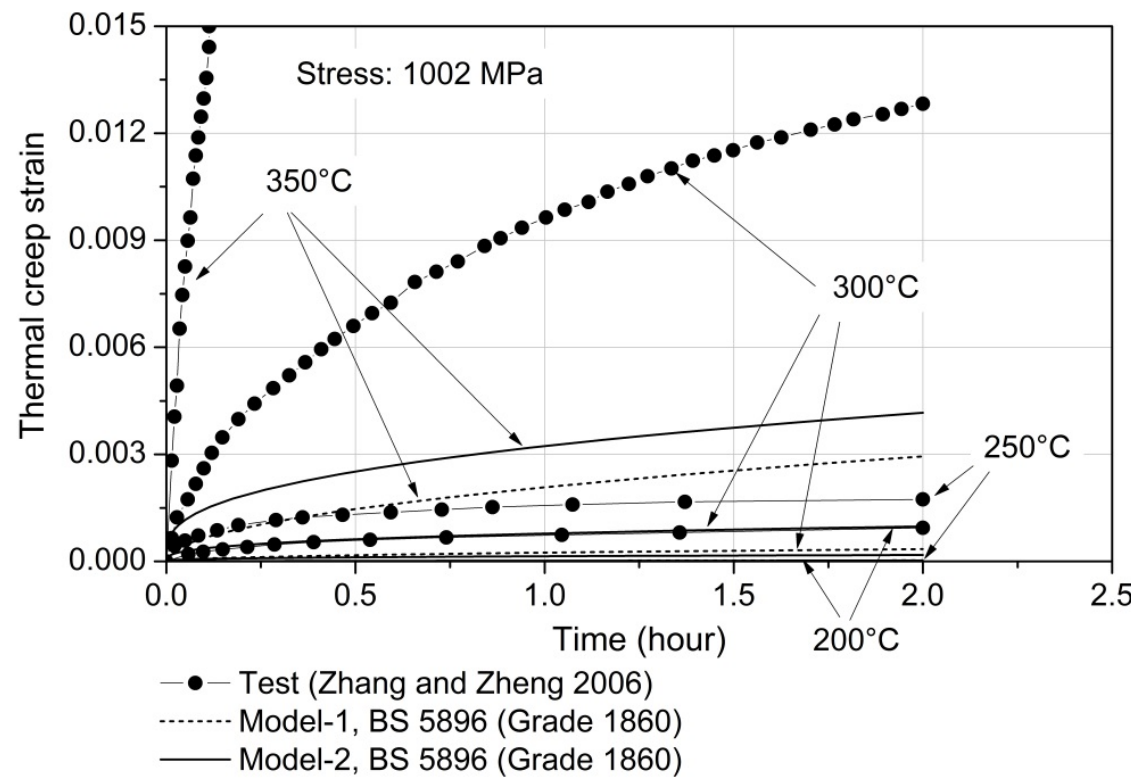

(b) Response under stress of $1002 \mathrm{MPa}$

Figure 5. Creep strains predicted by numerical model with thermal creep parameters of BS 5896 (Grade 1860) compared to test results (Zhang and Zheng 2006) 


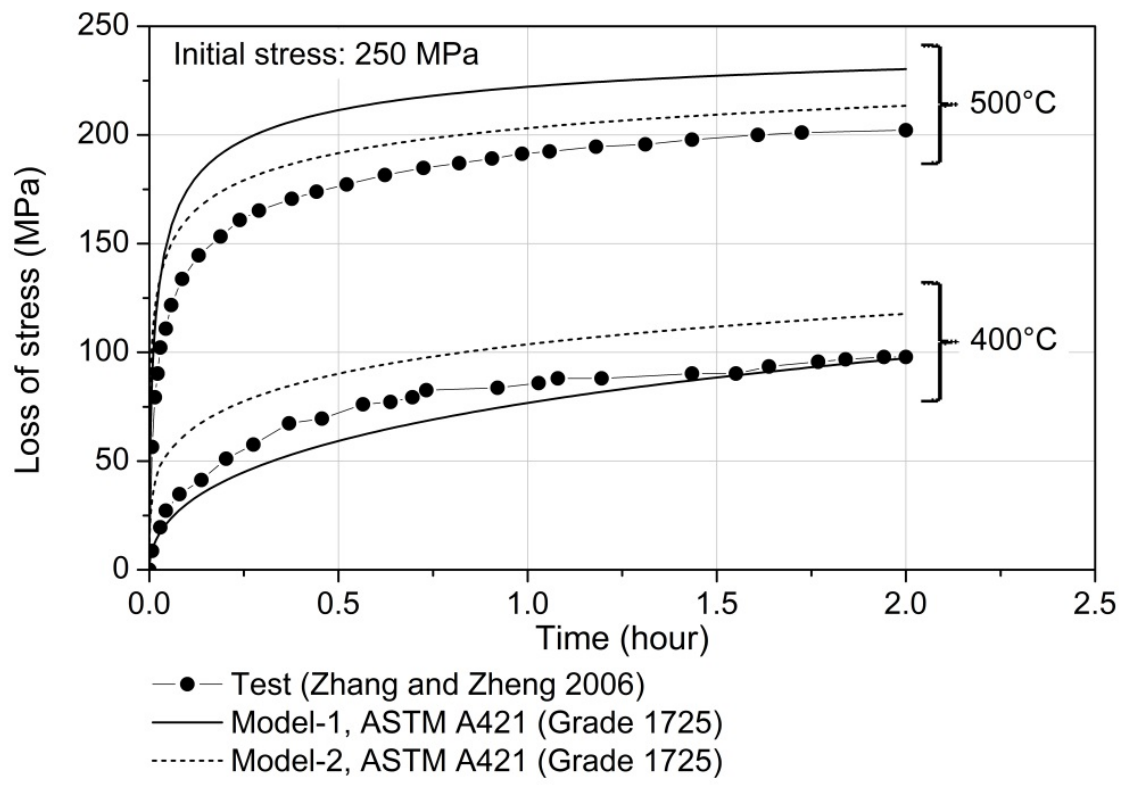

(a) Response under initial stress of $250 \mathrm{MPa}$

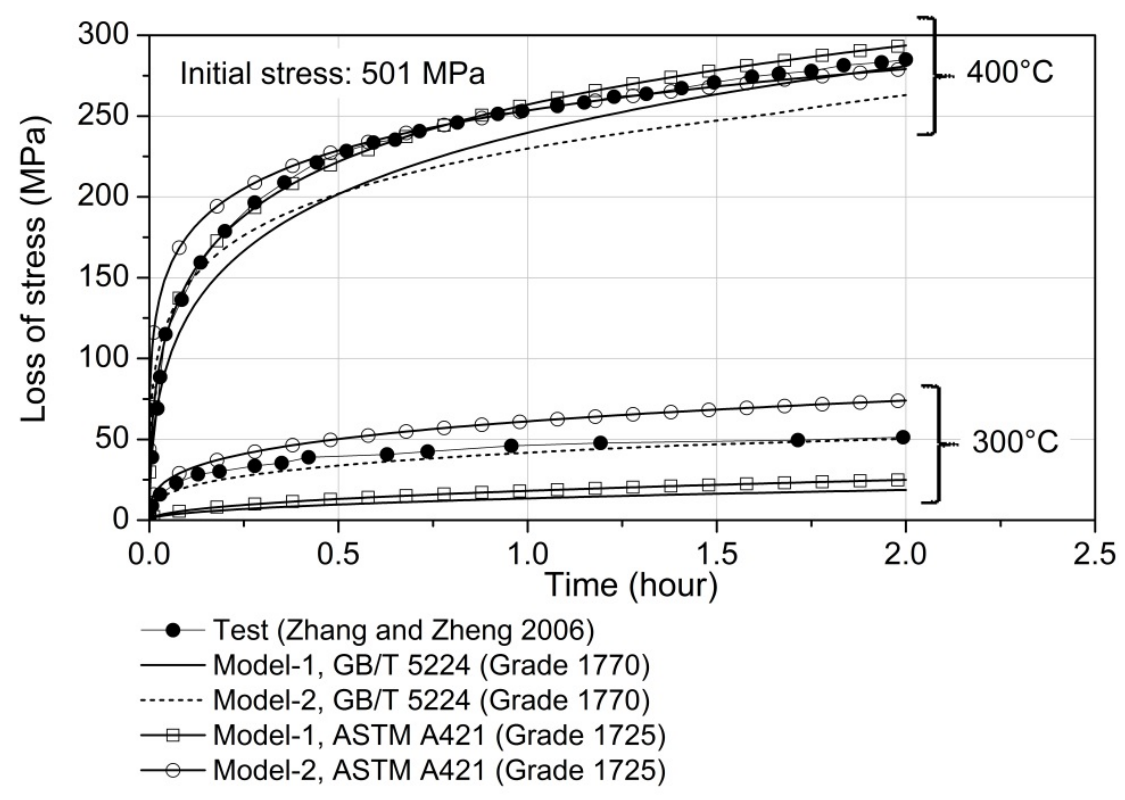

(b) Response under initial stress of $501 \mathrm{MPa}$

Figure 6. Relaxation predicted by numerical model with various thermal creep parameters compared to test results (Zhang and Zheng 2006) 


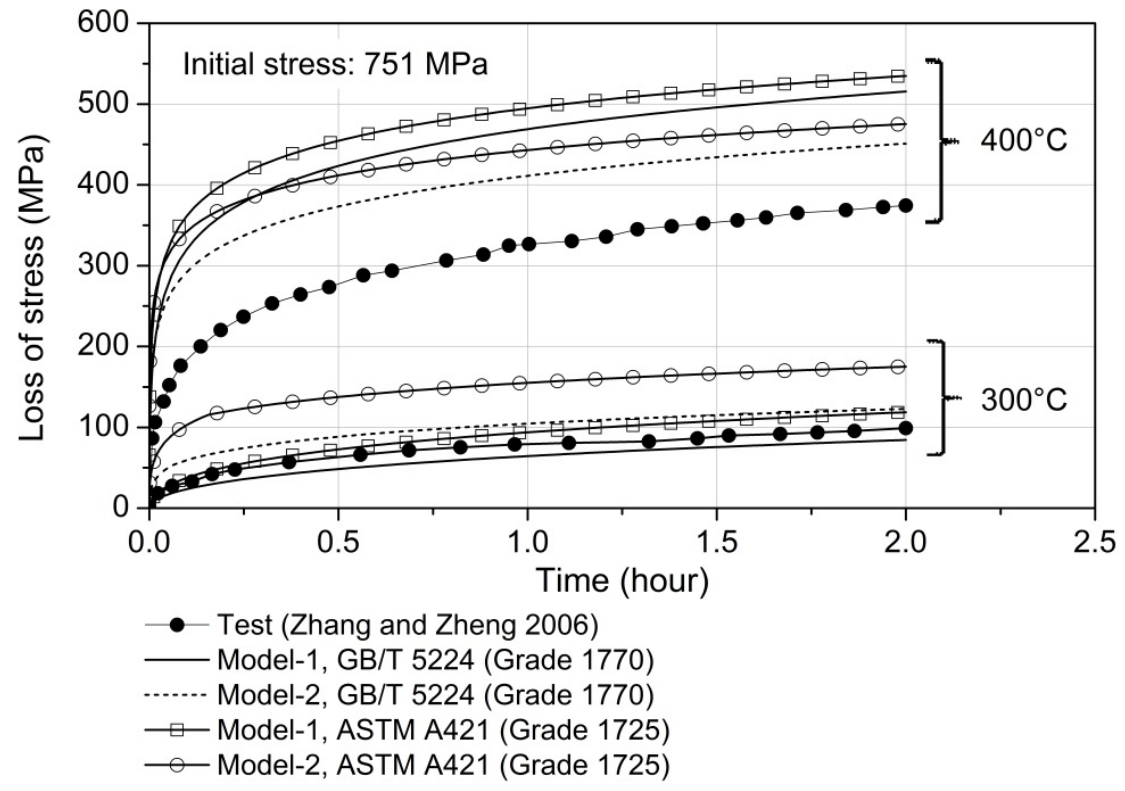

(c) Response under initial stress of $751 \mathrm{MPa}$

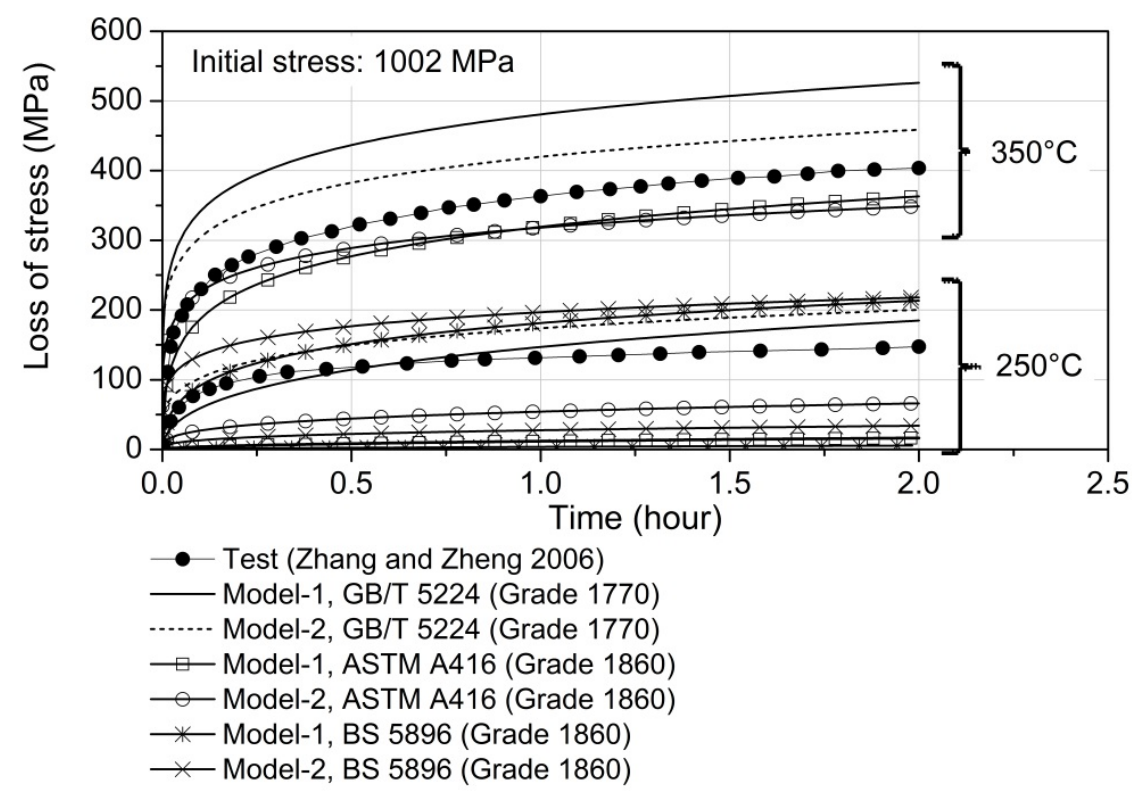

(d) Response under initial stress of 1002MPa

Figure 6. Relaxation predicted by numerical model with various thermal creep parameters compared to test results (Zhang and Zheng 2006) (continued) 


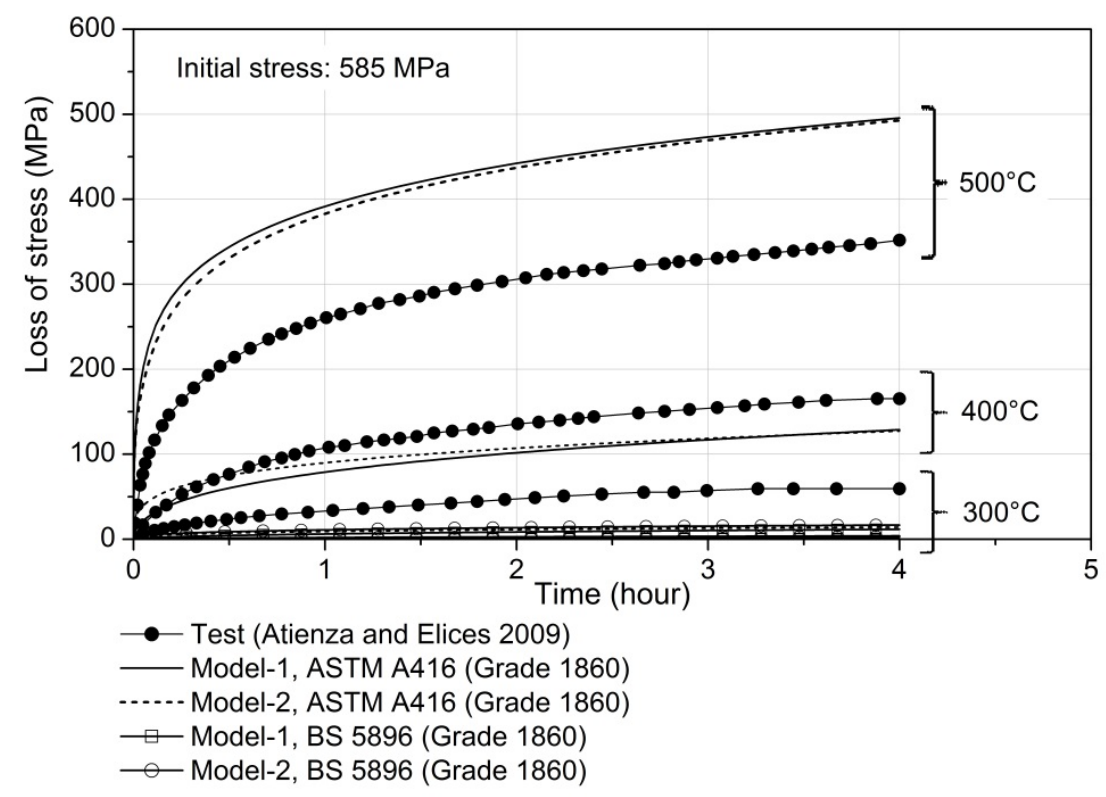

(a) Response under initial stress of 585MPa

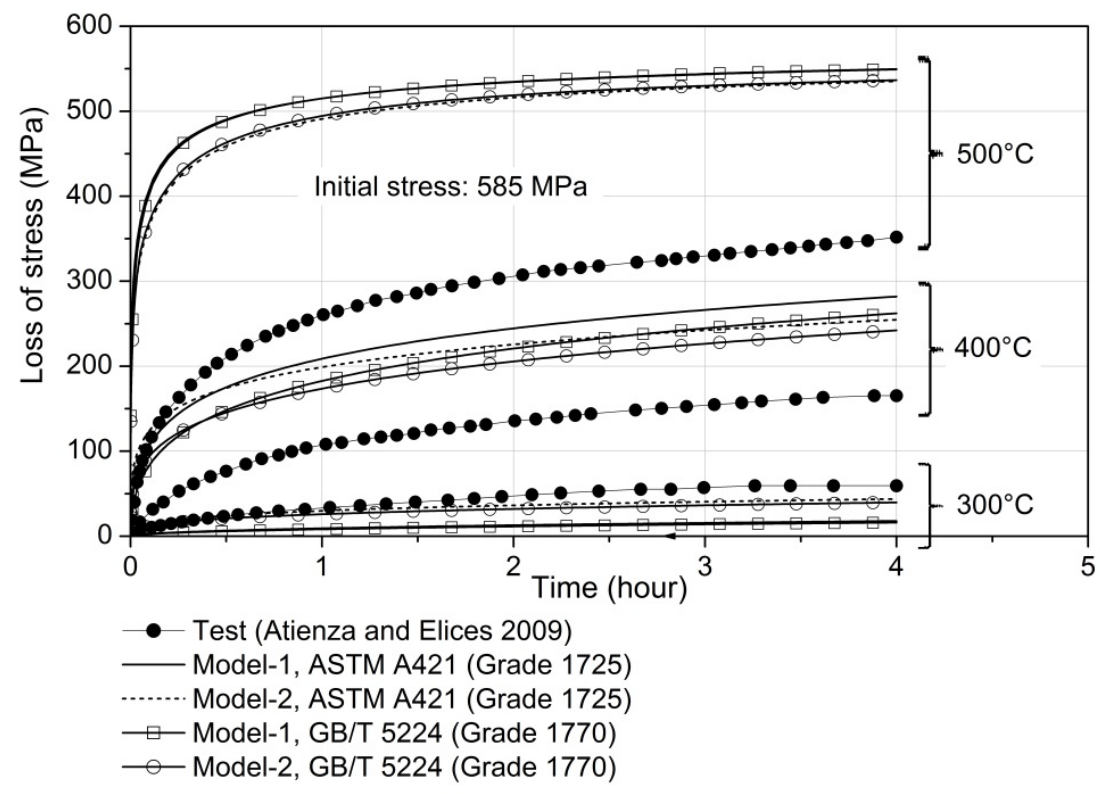

(b) Response under initial stress of 585MPa

Figure 7. Relaxation predicted by numerical model with various thermal creep parameters compared to test results (Atienza and Elices 2009) 


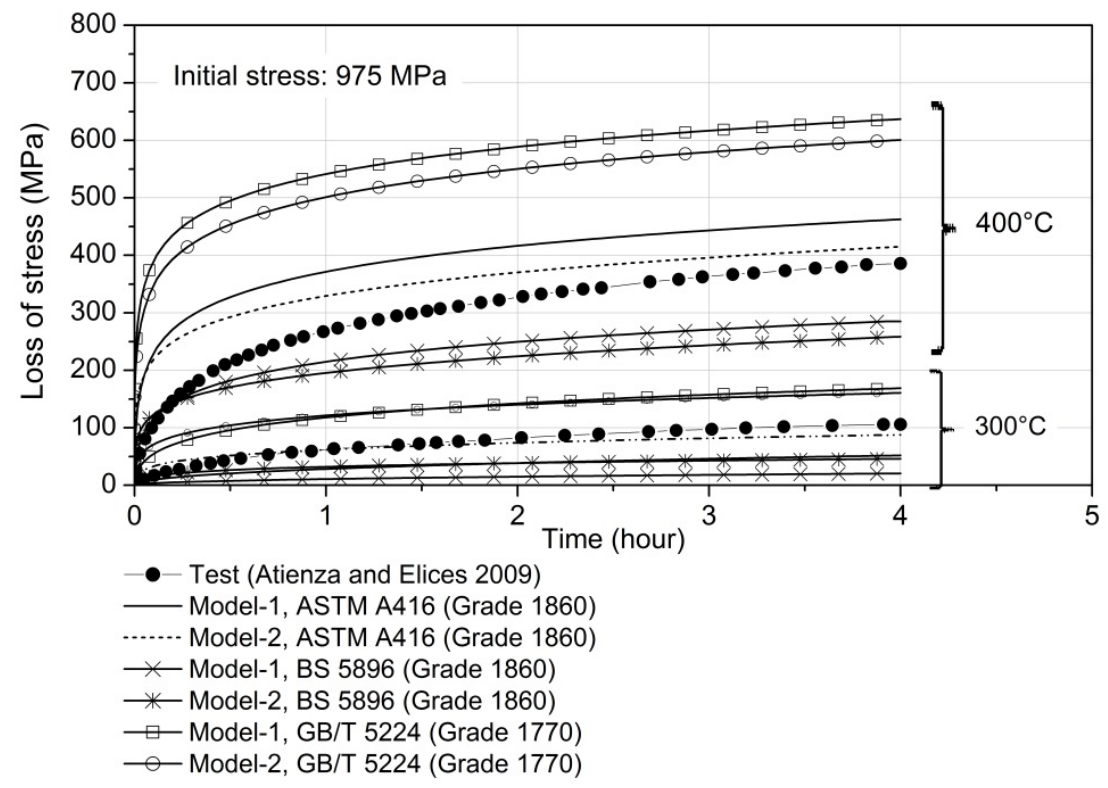

(c) Response under initial stress of 975MPa

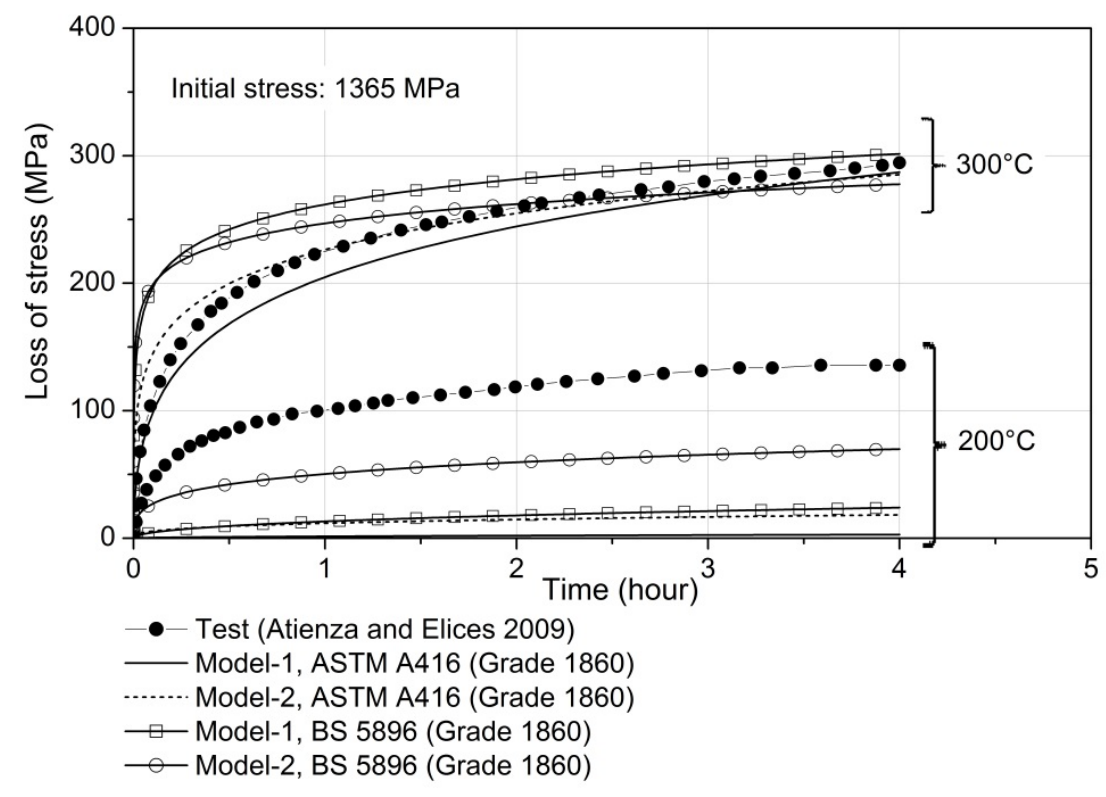

(d) Response under initial stress of 1365MPa

Figure 7. Relaxation predicted by numerical model with various thermal creep parameters compared to test results (Atienza and Elices 2009) (continued) 


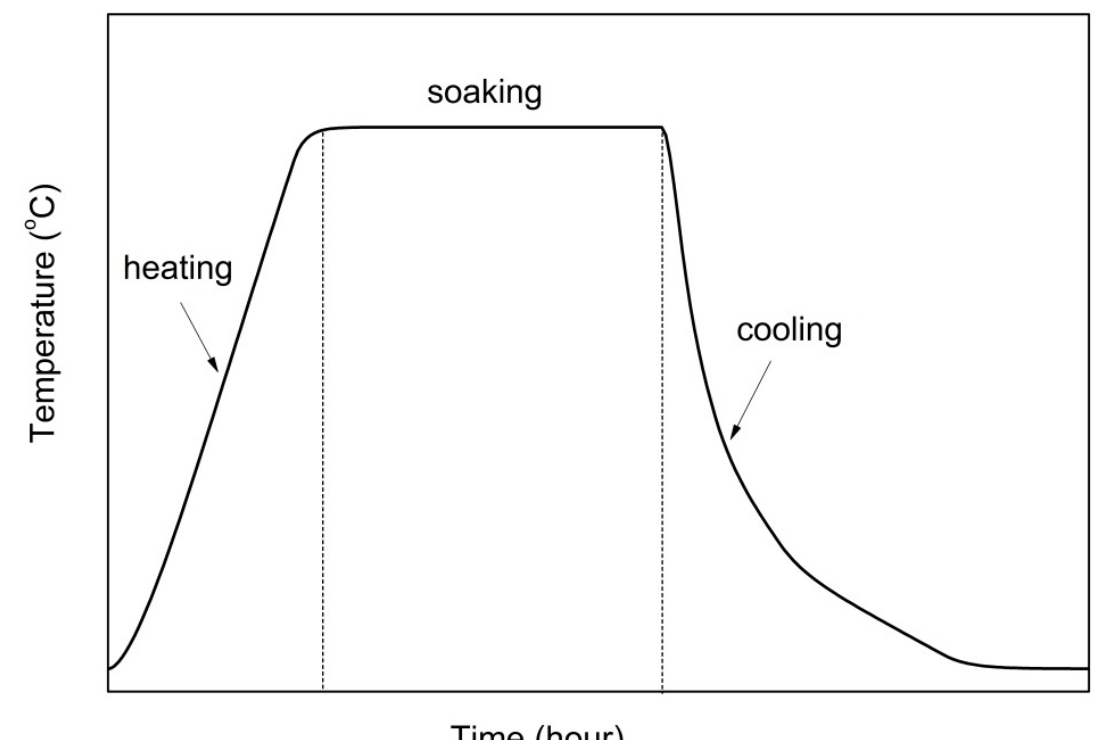

Time (hour)

Figure 8. Heating-soaking-cooling regime 


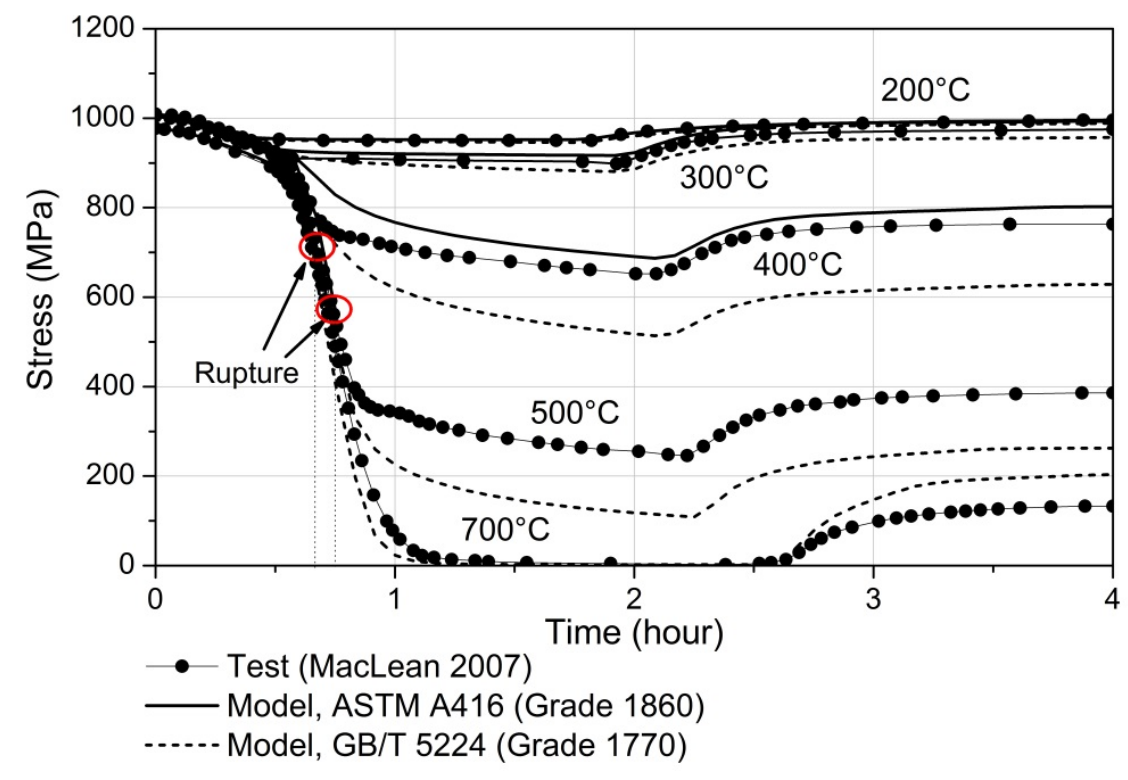

(a) Stress relaxation from numerical modelling and tests (MacLean 2007)

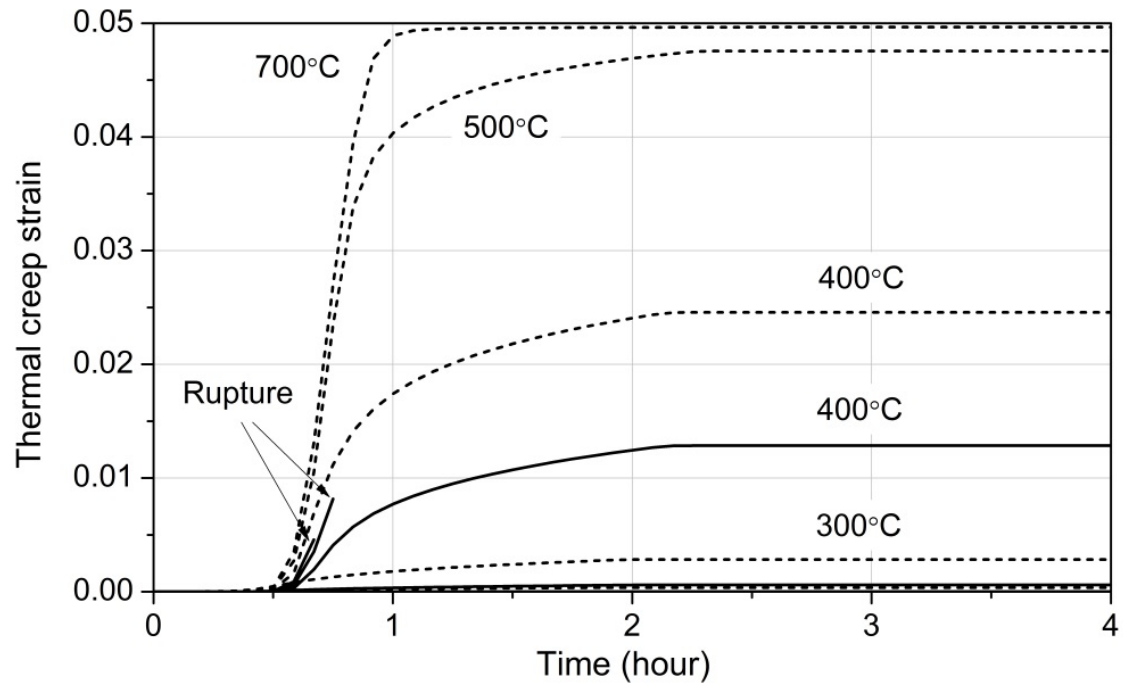

Model, ASTM A416 (Grade 1860)

-..---Model, GB/T 5224 (Grade 1770)

(b) Creep strain of heated region from numerical modelling

Figure 9. Transient relaxation and creep at various soaking temperatures 


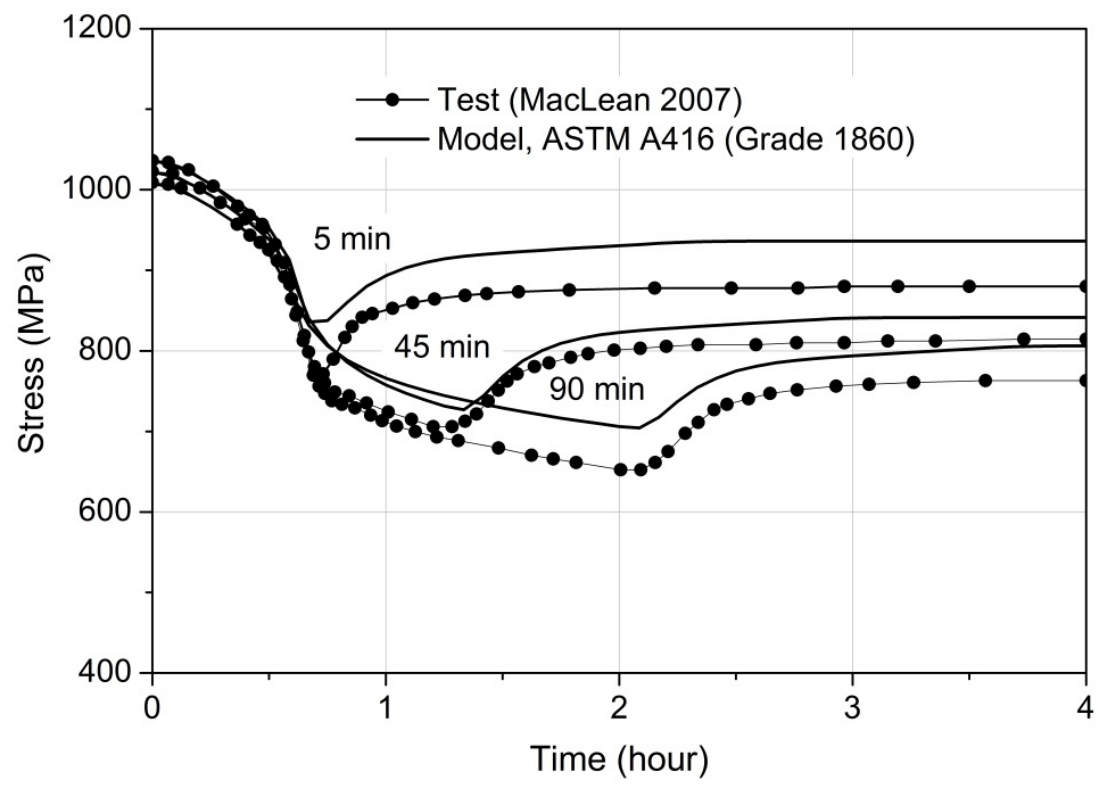

(a) Stress relaxation from numerical modelling and tests (MacLean 2007)

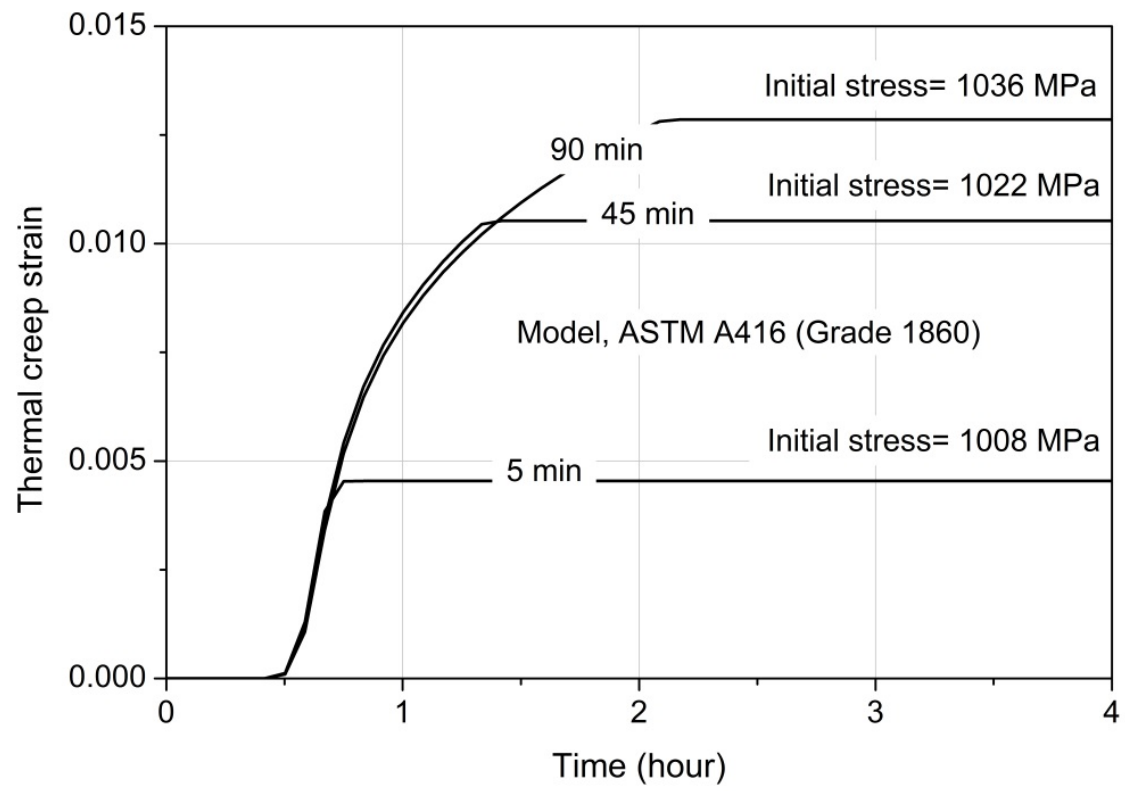

(b) Creep strain of heated region from numerical modelling

Figure 10. Transient relaxation and creep with various soaking time 


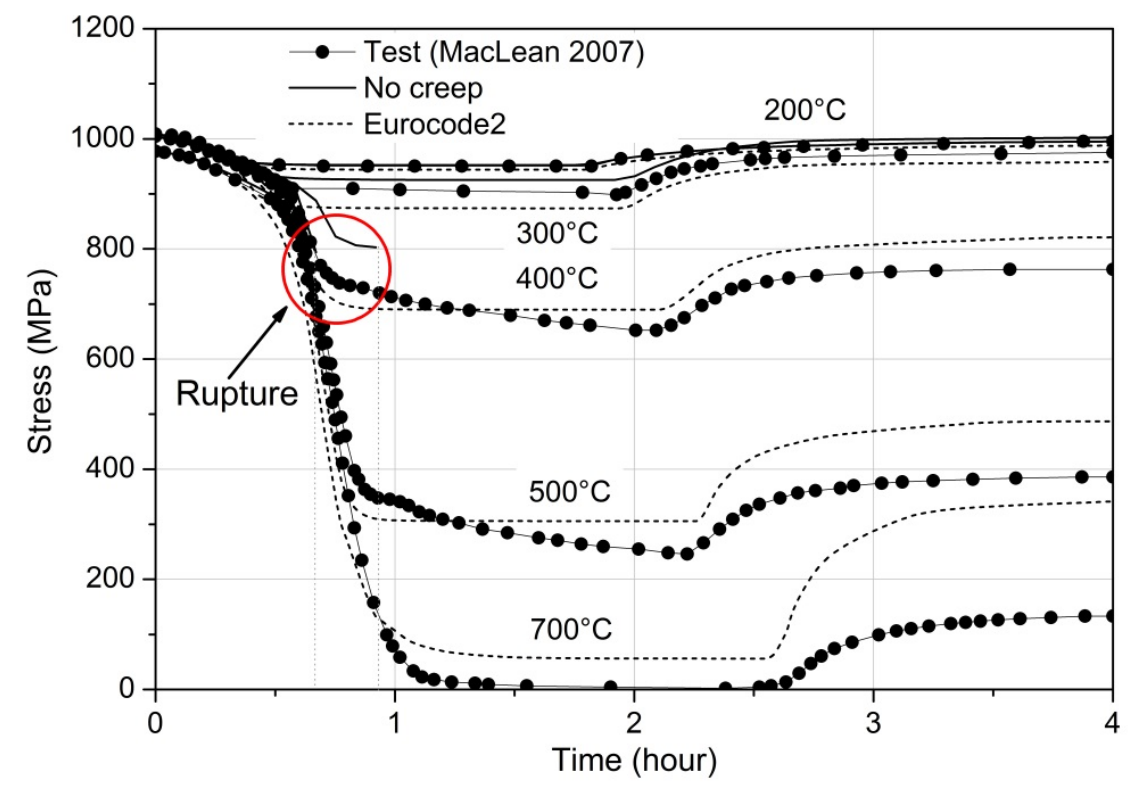

Figure 11. Transient relaxation predicted with and without consideration of creep 


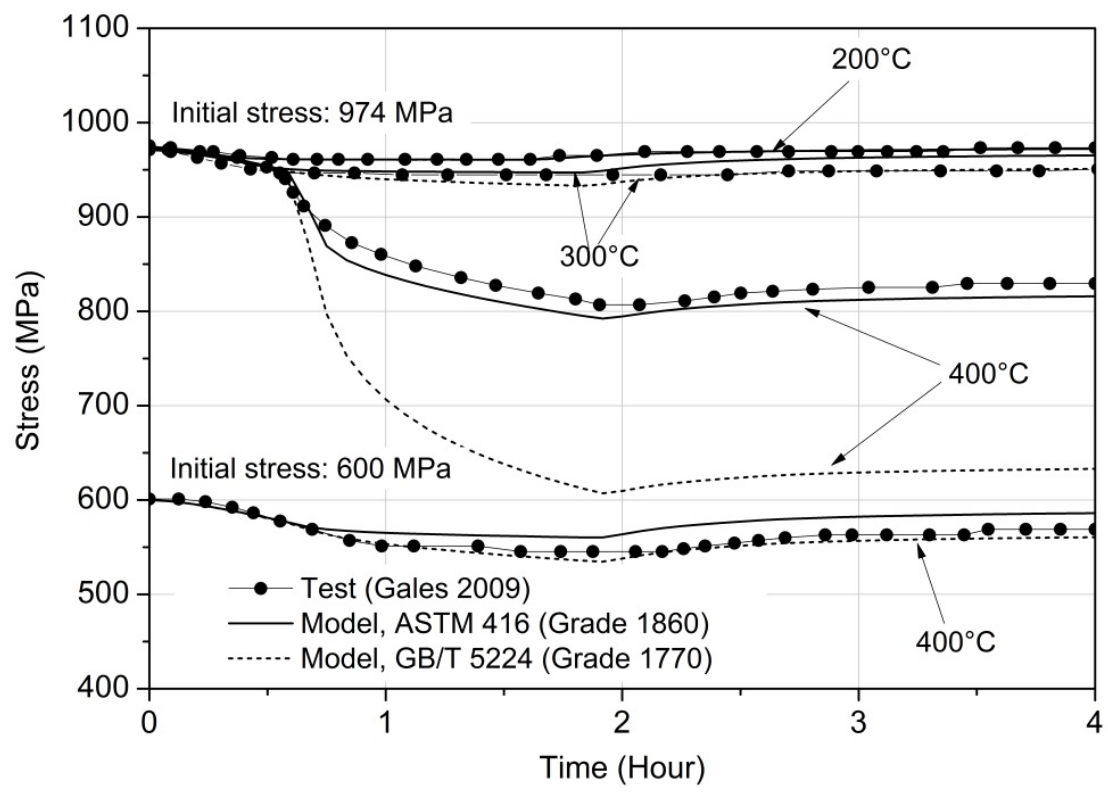

(a) Stress relaxation from numerical modelling and tests (Gales 2009)

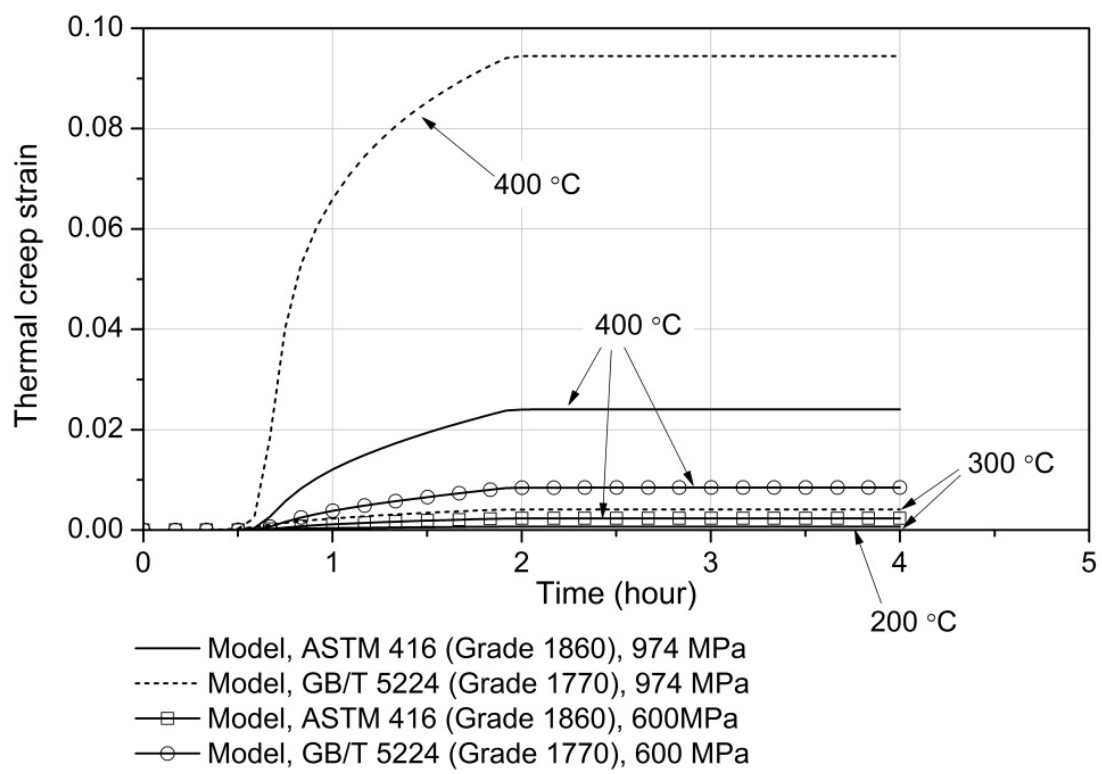

(b) Creep strain of heated region from numerical modelling

Figure 12. Transient relaxation and creep of tests at various soaking temperatures 


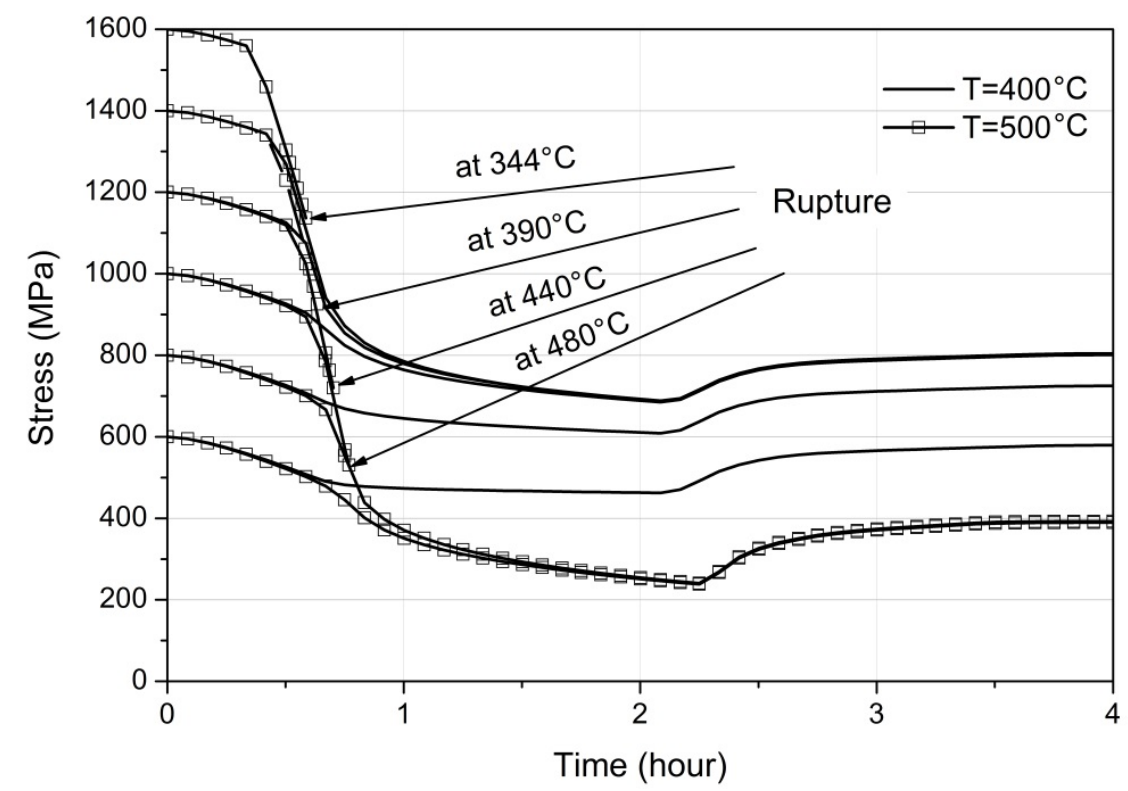

(a) Relaxation predicted by numerical model for various soaking temperatures and initial stresses

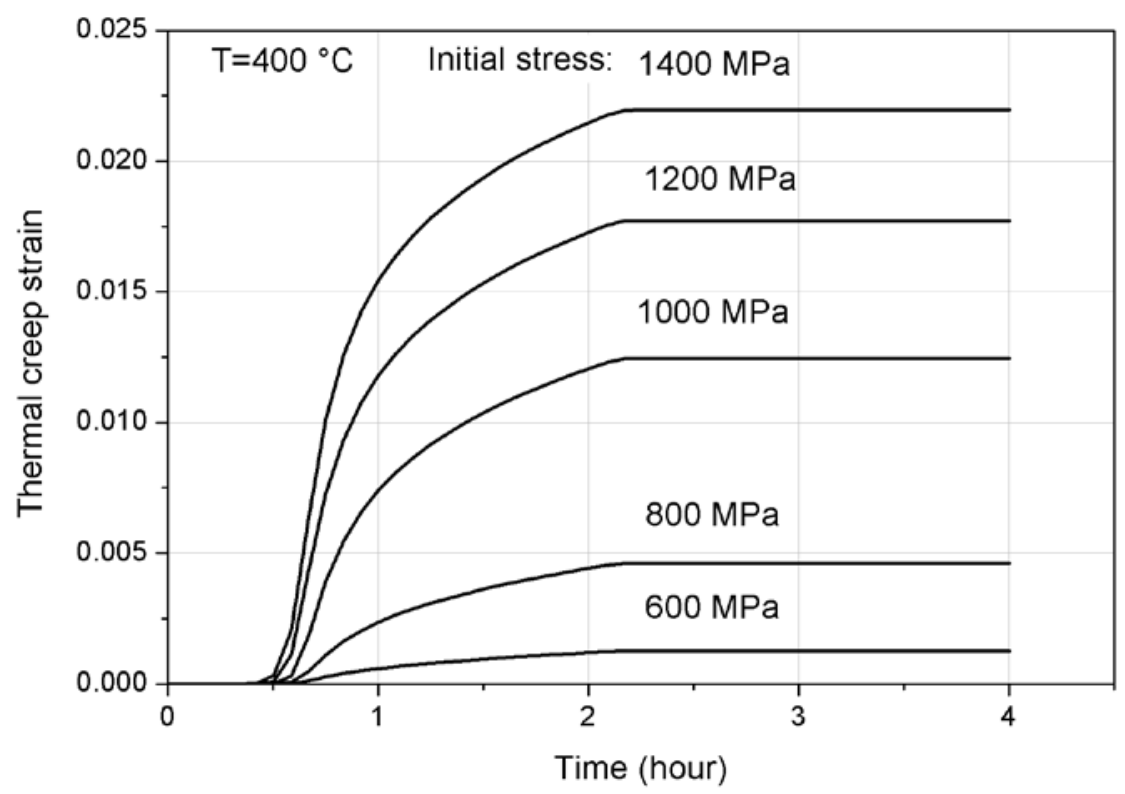

(b) Creep strain of heated region predicted by numerical model for cases without rupture

Figure 13. Transient relaxation and creep under various initial stresses 


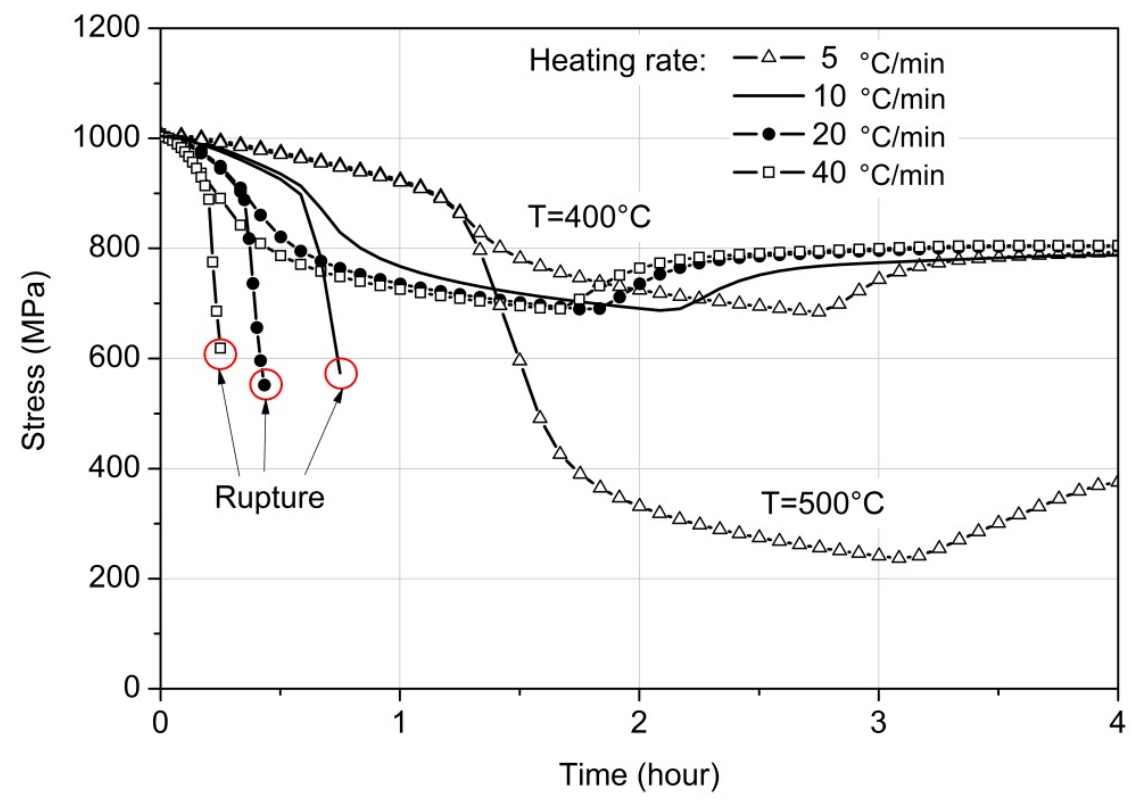

(a) Relaxation predicted by numerical model for various soaking temperatures and heating rates

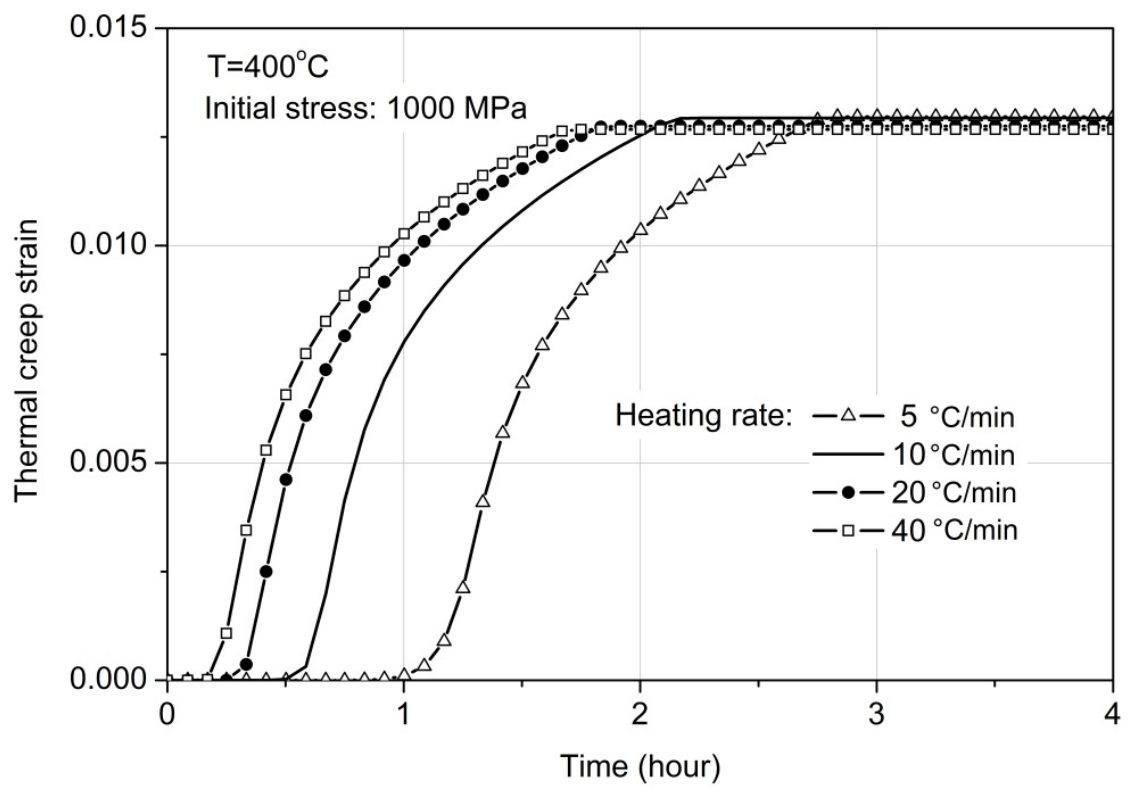

(b) Creep strain of heated region predicted by numerical model for cases without rupture

Figure 14. Transient relaxation and creep under various heating rates 


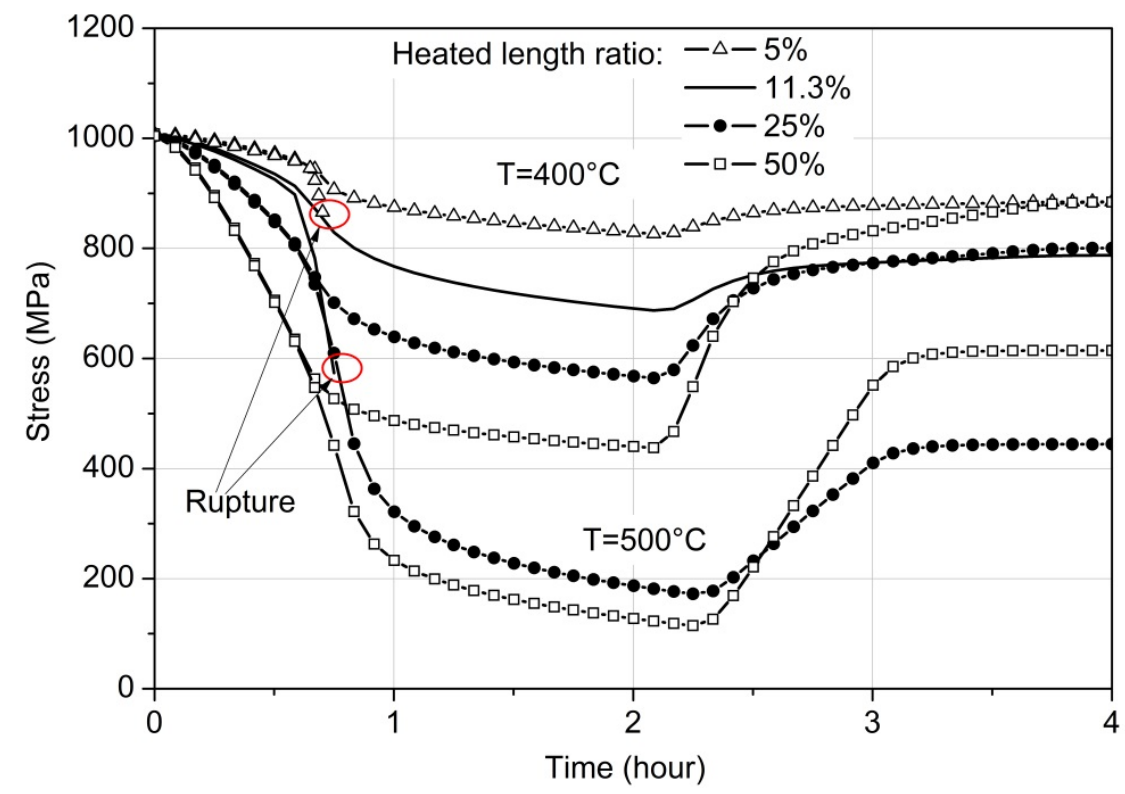

(a) Relaxation predicted by numerical model for various soaking temperatures and heated length ratios

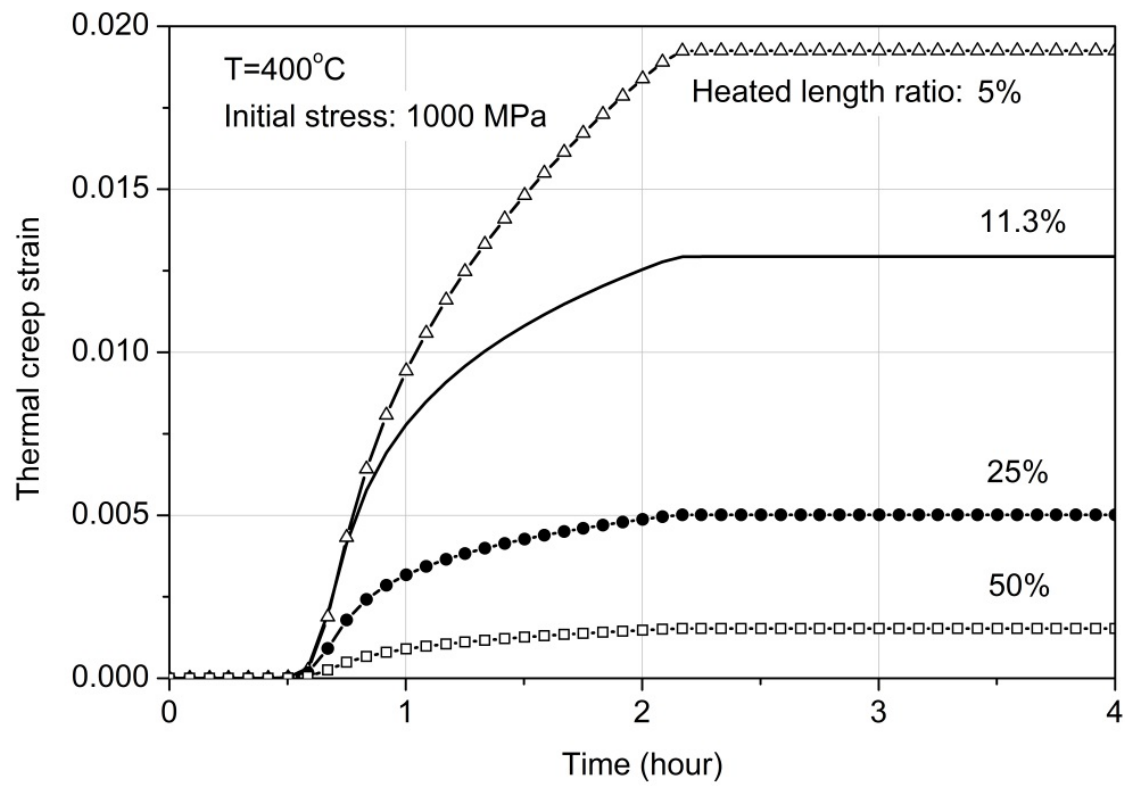

(b) Creep strain of heated region predicted by numerical model for cases without rupture

Figure 15. Transient relaxation and creep for various heated length ratios 


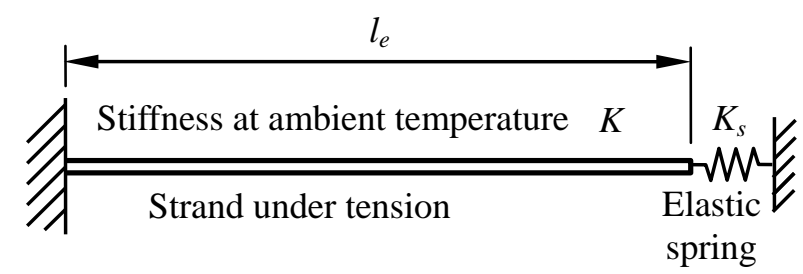

Figure 16. Schematic diagram of variation of boundary conditions 


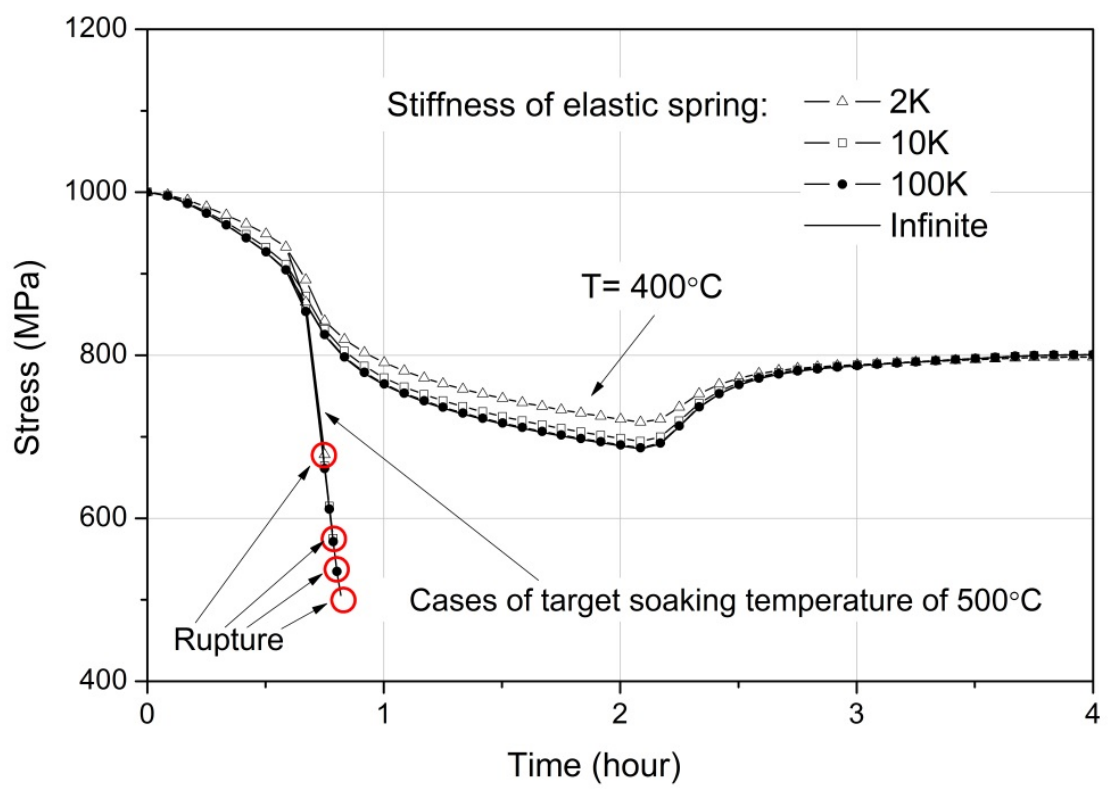

(a) Relaxation predicted by numerical model for various soaking temperatures and support stiffnesses

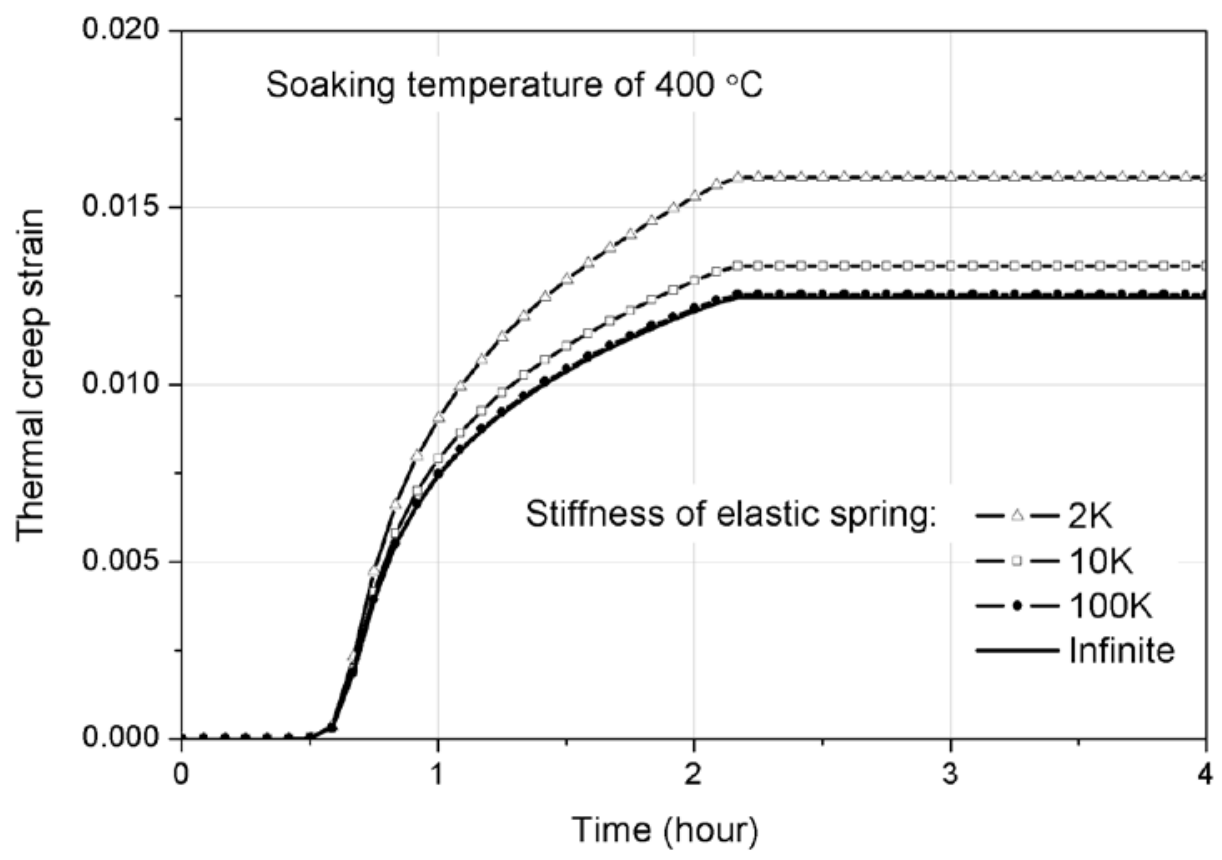

(b) Creep strain of heated region predicted by numerical model for cases without rupture

Figure 17. Transient relaxation and creep for various boundary conditions 


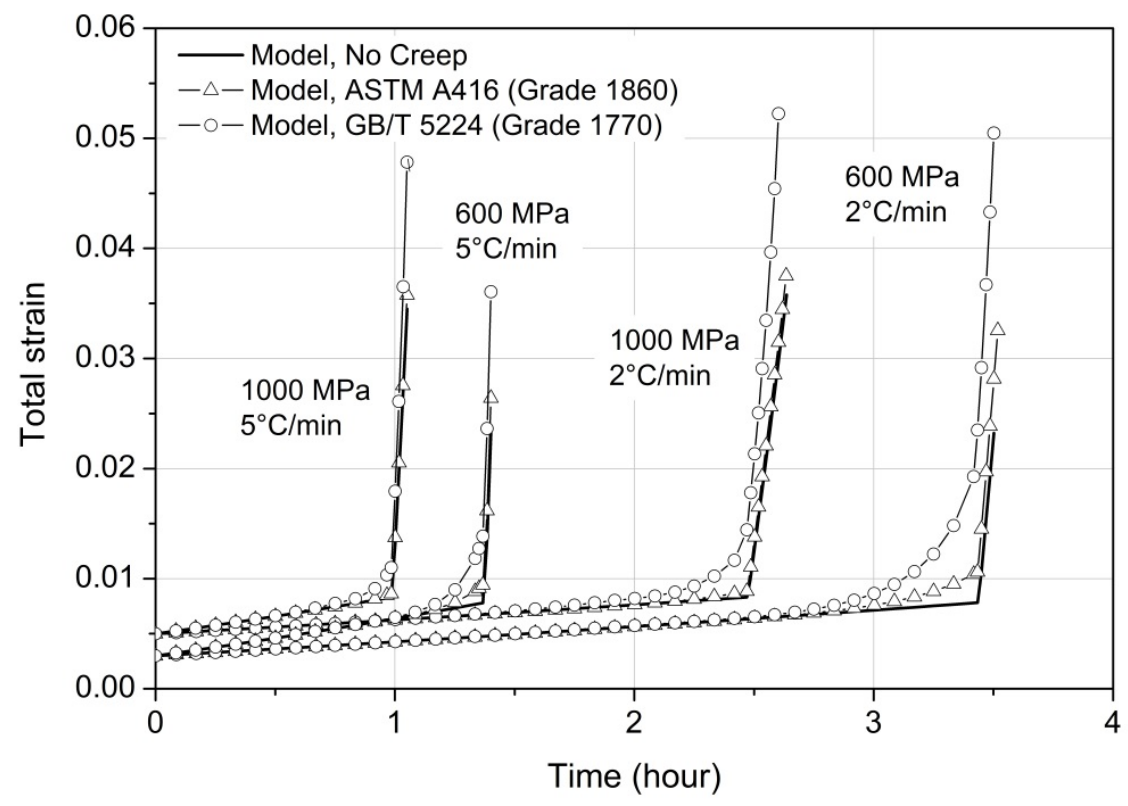

(a) Total strain of heated region

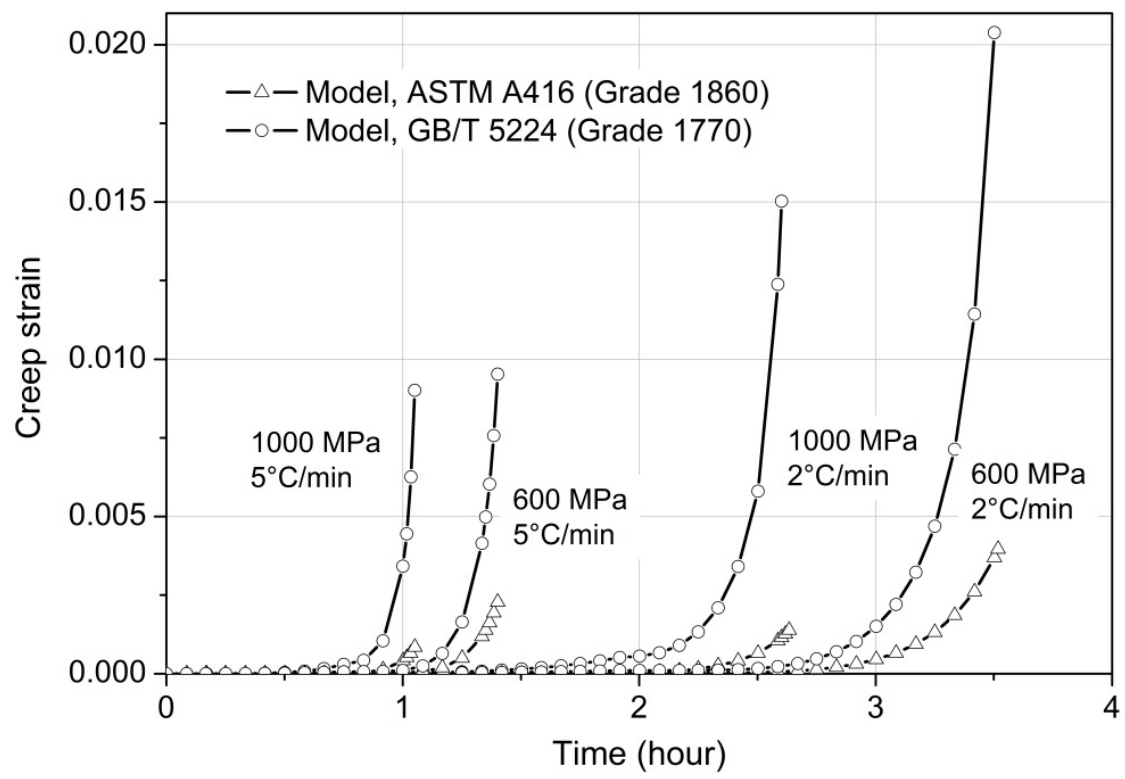

(b) Creep strain of heated region

Figure 18. Results of transient state analysis under different initial stresses and heating rates 
Table 1. Chemical composition of various prestressing steel (\%)

\begin{tabular}{cccc}
\hline & $\begin{array}{c}\text { BS 5896 } \\
\text { (Grade 1860) }\end{array}$ & $\begin{array}{c}\text { ASTM A416 } \\
\text { (Grade 1860) }\end{array}$ & $\begin{array}{c}\text { ASTM A421 } \\
\text { (Grade 1725) }\end{array}$ \\
\hline $\mathrm{C}$ & 0.9 & 0.8 & 0.79 \\
$\mathrm{Cr}$ & 0.011 & 0.04 & - \\
$\mathrm{Mn}$ & 0.66 & 0.87 & 0.78 \\
$\mathrm{P}$ & 0.007 & 0.023 & 0.012 \\
$\mathrm{Si}$ & 0.25 & 0.45 & 0.19 \\
$\mathrm{~S}$ & 0.014 & 0.012 & 0.031 \\
$\mathrm{Ni}$ & 0.021 & - & - \\
$\mathrm{Cu}$ & 0.011 & - & - \\
\hline
\end{tabular}

